\title{
JURISDIÇÃO E LITIGIOSIDADE: partes e instituições em conflito
}

\author{
Tese de Doutorado \\ Orientador: Prof. Associado Dr. Carlos Alberto de Salles
}

UNIVERSIDADE DE SÃO PAULO

FACULDADE DE DIREITO

São Paulo-SP 



\title{
JURISDIÇÃO E LITIGIOSIDADE: partes e instituições em conflito
}

\author{
Tese de Doutorado, apresentada à Banca \\ Examinadora do Programa de Pós-Graduação \\ em Direito, da Faculdade de Direito da \\ Universidade de São Paulo, na área de \\ concentração de Direito Processual Civil, sob a \\ orientação do Professor Associado Dr. Carlos \\ Alberto de Salles.
}

\section{UNIVERSIDADE DE SÃO PAULO}

FACULDADE DE DIREITO

São Paulo-SP 
Autorizo a reprodução e divulgação total ou parcial deste trabalho, por qualquer meio convencional ou eletrônico, para fins de estudo e pesquisa, desde que citada a fonte.

Serviço de Processos Técnicos da Biblioteca da Faculdade de Direito da Universidade de São Paulo

Takahashi, Bruno Jurisdição e Litigiosidade: partes e instituições em conflito / Bruno Takahashi; orientador Carlos Alberto de Salles. São Paulo, 2019.

$312 \mathrm{p}$.

Tese (Doutorado) - Faculdade de Direito - Universidade de São Paulo, 2019.

Orientador: Prof. Carlos Alberto de Salles

Notas de rodapé.

Inclui bibliografia

1. Processo Civil. 2. Jurisdição. 3. Litigiosidade. 4. Análise Institucional Comparada. 5. Acesso à Justiça. I. Salles, Carlos Alberto de. II. Título. 
Nome: Bruno Takahashi

Título: Jurisdição e Litigiosidade: partes e instituições em conflito

Tese de Doutorado, apresentada à Banca Examinadora do Programa de Pós-Graduação em Direito, da Faculdade de Direito da Universidade de São Paulo, na área de concentração de Direito Processual Civil

Aprovado em:

Banca Examinadora:

Prof. Dr. Instituição:

Julgamento: Assinatura:

Prof. Dr. Instituição:

Julgamento: Assinatura:

Prof. Dr. Instituição:

Julgamento: Assinatura:

Prof. Dr. Instituição:

Julgamento: Assinatura:

Prof. Dr. Instituição:

Julgamento: Assinatura:

Prof. Dr. Instituição:

Julgamento: Assinatura: 

À Olivia e à Violeta,

pelo decisivo apoio, cada qual à sua maneira. 



\section{RESUMO}

TAKAHASHI, Bruno. Jurisdição e Litigiosidade: partes e instituições em conflito. 2019. 312 p. Tese de Doutorado - Faculdade de Direito, Universidade de São Paulo, São Paulo, 2019.

A ideia de que haveria uma "explosão de litigiosidade" no Brasil costuma se basear unicamente no acúmulo de processos judiciais nos fóruns e tribunais, frequentemente ignorando a diversidade das partes envolvidas. A questão principal, porém, permanece deslocada: em vez de aferir se há ou não muitos processos no Judiciário, o que importa é saber se o processo judicial é a alternativa mais adequada (ou menos inadequada). De fato, observa-se que, até eventualmente se tornar uma disputa, o conflito passa por diferentes fases, estando sujeito a ampliações e reduções. Redimensionando o conceito de jurisdição, nota-se ainda que o processo judicial é somente uma das instituições disponíveis, nem sempre sendo a melhor. Isso exige uma análise comparativa das alternativas, em que também é relevante observar a dinâmica das partes. Nesse contexto, são propostos, metaforicamente, três movimentos: dar um passo para trás (esbarrando no conflito em vez de ficar restrito ao litígio judicial), olhar para os lados (enxergando as diversas instituições e processos jurisdicionais sem limitar o foco no Judiciário) e observar quem está presente (percebendo as características estruturais das partes em ação). Com base nesses movimentos, este trabalho defende que é possível traçar parâmetros para auxiliar na escolha do processo mais adequado para o tratamento de determinado conflito conforme as partes envolvidas e os objetivos que se pretende atingir, o que permitiria, além disso, analisar o cenário da "explosão de litigiosidade" sob outra perspectiva.

Palavras-Chave: direito processual, análise institucional comparada, litigiosidade, processos de solução de disputas, conflito, jurisdição, instituições, dinâmica da participação. 



\begin{abstract}
TAKAHASHI, Bruno. Jurisdiction and Litigation: Parties and Institutions in Conflict. 2019. 312 p. PhD Thesis - Faculty of Law, University of São Paulo, São Paulo, 2019.

The idea that there would be an "explosion of litigation" in Brazil is usually based only on the number of lawsuits, often ignoring the diversity of the parties involved. The main issue, however, remains displaced: instead of assessing whether there are many lawsuits, what matters is knowing whether the Judiciary is the most appropriate (or least inadequate) alternative. In this context, it is observed that, until eventually becoming a legal dispute, the conflict goes through different stages - being subject to extensions and reductions - and, sometimes, even gets lost on the way. Reviewing the concept of jurisdiction, it is noted that adjudication by a judge is only one of the options available, though not always the most adequate (or less inadequate). This requires a comparative analysis of the alternatives, in which it is also relevant to observe the dynamics of the parties. In this context, three movements are, metaphorically, proposed: taking a step backwards (bumping into conflict instead of being restricted to judicial dispute), looking sideways (seeing the various institutions without limiting the focus on courts) and observing who is present (taking notice of the structural characteristics of the parties in action). Based on these movements, this thesis argues that it is possible to draw parameters to help in choosing the most appropriate process for the treatment of a given conflict according to the parties involved and the objectives to be achieved. This would also allow for the analysis of the "explosion of litigation" scenario from another perspective.
\end{abstract}

Keywords: procedural law, comparative institutional analysis, litigation, conflict resolution, conflict, jurisdiction, institutions, dynamics of participation. 



\section{RIASSUNTO}

TAKAHASHI, Bruno. Giurisdizione e litigiosità: parti e istituzioni in conflitto. 2019. 312

p. Tesi di dottorato - Facoltà di Giurisprudenza, Università di São Paulo, São Paulo, 2019.

L'idea che ci sia in Brasile un" "esplosione di litigi" di solito si basa esclusivamente sull' accumulo di processi giudiziari nei tribunali e trascura quanto siano diversi i soggetti coinvolti. La questione principale, tuttavia, rimane fuori focus: piuttosto che concentrarsi sul numero di processi nei tribunali, bisognerebbe valutare se il processo giudiziario costituisce l'alternativa più adatta $o$, semplicemente, il meno peggio. Infatti, si osserva che, prima di diventare una disputa vera e propria, il conflitto attraversa diverse fasi, tra le quali espansioni e riduzioni, e persino la possibilità di perdersi lungo la via. Il ridimensionamento della nozione di giurisdizione permette di osservare che il processo giudiziario è soltanto una delle opzioni disponibili e non necessariamente la migliore. Sarebbe opportuna, pertanto, un'analisi comparativa delle alternative, basata sulle dinamiche delle parti. In questo contesto, sono proposti metaforicamente tre movimenti: quelle di 'fare un passo indietro' (arrivando al conflitto, non solo al processo giudiziario), 'guardarsi intorno (valutando altre istituzioni, non soltanto i tribunali) e 'osservare gli astanti' (cioè, le caratteristiche strutturali delle parti in azione). Su tali ipotesi, la tesi sostiene che è possibile trovare dei parametri che possano aiutare nella scelta del processo più appropriato per il trattamento di un determinato conflitto in base alle parti coinvolte e agli obiettivi che ci si prefiggono. Di conseguenza, si può analizzare lo scenario di “ esplosione di litigi" da un'altra prospettiva.

Parole chiave: diritto processuale, analisi comparativa istituzionale, litigiosità, processi di risoluzione delle controversie, conflitto, giurisdizione, istituzioni, dinamiche di partecipazione. 



\section{AGRADECIMENTOS}

Se o processo não é ponto de partida e nem ponto de chegada, cabe valorizar o caminho que se faz ao caminhar. Agradeço a todos que, de alguma forma, tornaram o percurso menos tortuoso e, frequentemente, muito agradável.

Em particular, sou grato ao professor Carlos Alberto de Salles pelo apoio constante e pela orientação precisa desde os tempos do mestrado. Esta tese, em grande parte, é fruto das diversas conversas com o professor Salles e da leitura de sua obra. Seja do ponto de vista teórico, seja do pessoal, ele é um grande exemplo para mim.

Também agradeço ao professor Kazuo Watanabe pelas inúmeras lições a cada nova batalha para tentar fazer a ordem jurídica mais justa. Do mesmo modo, sou grato ao professor Antonio Rodrigues de Freitas Jr., que generosamente me acolheu em seus projetos acadêmicos e com quem pude debater aspectos centrais deste trabalho.

Pelas valiosas sugestões durante a Banca de Qualificação, e fora dela, agradeço aos professores Susana Henriques da Costa e Paulo Eduardo Alves da Silva. Devo uma menção especial à professora Ada Pellegrini Grinover, que esteve presente nas Bancas de Qualificação e de Defesa do mestrado e me deixou amáveis palavras de incentivo para persistir na trajetória acadêmica.

Este trabalho é mais um passo na caminhada que teve início na Iniciação Científica durante a Graduação em Letras. Embora voltado a um tema tão distante como o gênero fantástico nos contos de Machado de Assis, retrospectivamente percebo a importância que aqueles dois anos como bolsista do CNPq tiveram na minha formação como pesquisador. Por isso, agradeço à minha primeira orientadora, professora Maria Aparecida Junqueira.

$\mathrm{O}$ começo desta pesquisa coincidiu com o período que estive como pesquisador visitante na Universidade de Osaka. Por isso, sou novamente grato ao professor Tsuneo Niki, por ter me aceito naquela instituição e pelo contato mantido desde então. Também agradeço aos professores Akiyo Shimamura, Luis Pedriza e Kota Fukui pelas explicações acerca do sistema judicial japonês e que, indiretamente, foram de extrema utilidade para a análise do contexto brasileiro. 

Durante o doutorado, tive a oportunidade de passar dois intensos meses como pesquisador na Universidade de Wisconsin-Madison. Pela admissão no Global Legal Studies Center, agradeço às professoras Sumudu Atapattu e Alexandra Huneeus. Sou extremamente grato ao professor Marc Galanter, que foi um verdadeiro anfitrião em Madison, dispondo-se a me encontrar semanalmente e a esclarecer minhas mais diversas dúvidas, sempre com uma paciência e uma humildade admiráveis. Também agradeço ao professor Neil Komesar por discutir meu projeto de pesquisa, bem como por me auxiliar com textos e esclarecimentos acerca da análise institucional comparada. Pela troca de experiências no período, sou igualmente grato aos professores Jeff Bowen e Boaventura de Sousa Santos, bem como a Wenjie Hu, Aldar Paulo André Silva Nassar e Aldar Chirninov.

Se o direito dos livros e o direito em ação formam partes de uma mesma realidade multifacetada, a teoria não pode se dissociar da prática. Minha experiência profissional seria muito menos gratificante se não fosse o apoio da Desembargadora Federal Daldice Santana, a quem sou especialmente grato. Muitas das reflexões presentes nesta tese decorreram das inúmeras conversas, projetos e inquietações compartilhadas com ela, seja na época do Gabinete da Conciliação, seja no Comitê Gestor Nacional de Conciliação.

Entre as pessoas que foram fundamentais durante o período do doutorado, tanto pela troca de ideias como pela imprescindível amizade agradeço, em particular, a Márcia Hoffmann do Amaral e Silva Turri, a Herbert Cornelio Pieter de Bruyn Junior e a Mauro Spalding. Por tudo isso e pela leitura crítica da versão preliminar do trabalho, sou grato a Carlos Gustavo Moimaz Marques.

Pelo imprescindível apoio institucional para o desenvolvimento desta tese, sou grato aos Desembargadores Federais Therezinha Cazerta, Paulo Fontes e José Marcos Lunardelli. Do mesmo modo, agradeço aos servidores da $2^{\mathrm{a}}$ Vara Previdenciária, da $1^{\mathrm{a}}$ Vara Federal de Naviraí, do Gabinete da Conciliação e da Central de Conciliação de São Paulo pelo convívio diário em épocas que coincidiram com o doutorado. Pelo auxílio na pesquisa bibliográfica, agradeço aos servidores das Bibliotecas do Tribunal Regional

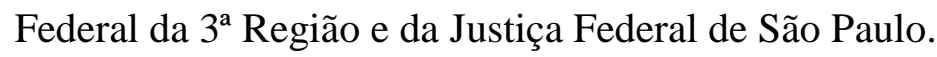

Aos amigos Sallesianos, agradeço por todo o apoio e incentivo prestados durante toda a elaboração deste trabalho. Em particular, agradeço a Alex Alckmin de Abreu Montenegro Zamboni, Amanda de Araujo Guimarães, Bruna Braga da Silveira, Bruno Lopes Megna, Maria Cecília de Araujo Asperti, Julio Oliveira e Marcela de Oliveira Rama. 

Também sou grato a professora Daniela Monteiro Gabbay, com quem pude compartilhar diversos projetos acadêmicos nos últimos anos e que foram fundamentais para o desenvolvimento deste trabalho. Ao professor Marco Antônio Garcia Lopes Lorencini manifesto meus sinceros agradecimentos não só pela troca de reflexões sobre os meios consensuais, mas, sobretudo, pelas reconfortantes palavras de apoio em um dos momentos mais críticos da pesquisa.

Em momentos diversos do percurso, muitas pessoas gentilmente contribuíram com sugestões que foram valiosas para a concretização do trabalho. Sou grato, em especial, a Zélia Luiza Pierdoná, Fernanda Tartuce, Yuri Kuroda Nabeshima, Ernani Shoiti Oda, Márcio Hayashi, Marcos Rolim da Silva, Marco Aurélio Serau Junior e Alexandre Schumacher Triches.

No desenvolvimento da pesquisa, pude apresentar conclusões parciais do trabalho nos Encontros Anuais da Law and Society Association de 2016 e de 2017; no XI Congresso Internacional de Estudos Japoneses no Brasil em 2016; e no Brazil-Japan Litigation and Society Seminar em 2018. Sou grato a todos os comentários recebidos nestas ocasiões e que auxiliaram no aprimoramento da pesquisa.

Ao João Rodrigues de Jesus, que, sempre com a competência habitual, corrige minhas redações desde a época do colégio, sou grato pela imprescindível revisão do texto original.

Sem o apoio familiar, nada seria possível ou, se possível, não valeria a pena. Por isso, agradeço a minha mãe, Keiko, ao meu pai, Martinho, ao meu irmão, Daniel, a minha cunhada, Mitie, e aos meus dois sobrinhos, Arthur e Pedro. Ao meu pai, em especial, agradeço também pela valiosa e atenta leitura crítica que fez deste trabalho.

Por me fazer acreditar que sempre é possível melhorar um pouco mais, dando-me o suporte necessário para prosseguir nos estudos e, sobretudo, por me aguentar nos momentos mais estressantes da pesquisa (e também fora deles), agradeço à minha esposa Olivia. A nossa filha, Violeta, agradeço pela alegria que trouxe desde a sua chegada, permitindo que eu olhasse o processo - e o mundo - sob outra perspectiva. 

“(...) é claro que explicar os processos não é suficiente para ninguém; não temos outra opção além de vivê-los, e ao vivê-los é que se aprende, mas também é como se cometem os erros e como se perde o rumo."

- Mario Levrero ${ }^{1}$

“- Todos aspiram à lei-diz o homem. - Como se explica que em tantos anos ninguém além de mim pediu para entrar?

O porteiro percebe que o homem já está no fim e para ainda alcançar sua audição em declínio ele berra:

- Aqui ninguém mais podia ser admitido, pois esta entrada estava destinada só a você. Agora eu vou embora e fecho-a"

- Franz Kafka ${ }^{2}$

${ }^{1} O$ romance luminoso. Tradução de Antônio Xerxenesky. Livro eletrônico. São Paulo: Companhia das Letras, 2018, pos.82.

${ }^{2}$ Diante da lei. In: Um médico rural. Tradução de Modesto Carone. $1^{\text {a }}$ reimpr. São Paulo: Companhia das Letras, 2001, p.29. 



\section{ÍNDICE DE FIGURAS}

Figura 1. O conflito como contraposição de interesses ou como contraposição de movimentos 20

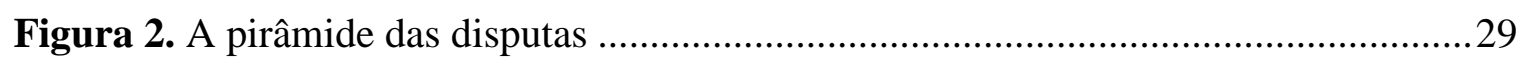

Figura 3. Do conflito ao conflito intersubjetivo de justiça (e daí em diante) ....................31

Figura 4. Modelo conceitual multidimensional da mobilização legal ..............................52

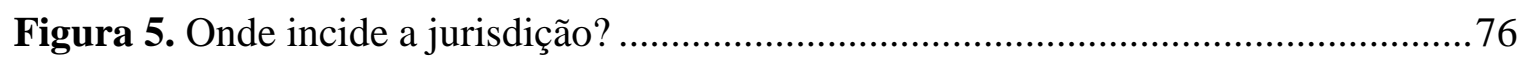

Figura 6. As instituições entre o estatal e o não-estatal.................................................. 79

Figura 7. Os processos institucionais típicos e atípicos ............................................... 85

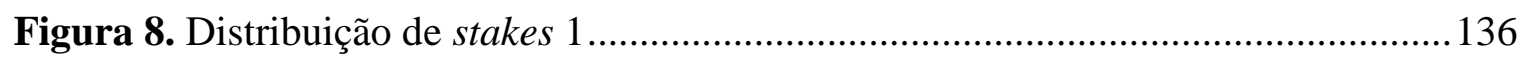

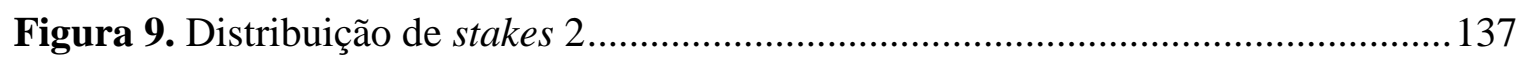

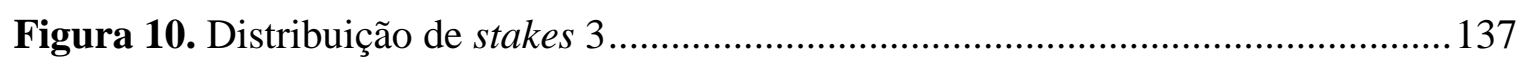

Figura 11. Pontos em comum entre Galanter e Komesar. ............................................ 143

Figura 12. Distribuição de stakes 4. Os efeitos da repetição......................................... 151

Figura 13. Um quadro de perguntas para a análise institucional comparada. .................253 



\section{SUMÁRIO}

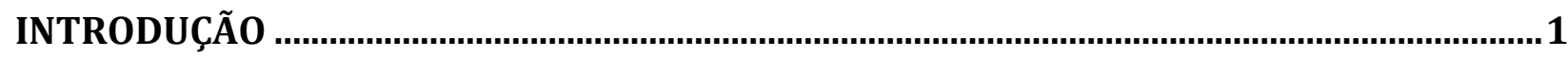

CAPÍTULO 1. DANDO UM PASSO PARA TRÁS: DO LITÍGIO JUDICAL PARA O

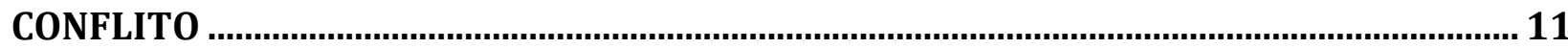

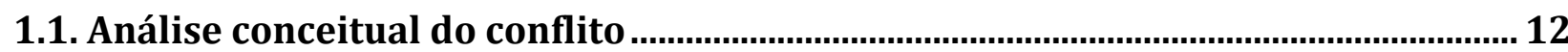

1.1.1. Da contraposição de interesses para a contraposição de movimentos 12

1.1.1.1. Follett e Deutsch : o conflito como contraposição de movimentos ........ 13

1.1.1.2. Carnelutti: o conflito como contraposição de interesses ............................ 17

1.1.1.3. Comparando os conceitos ................................................................................. 20

1.1.2.0 conflito de justiça e o conflito intersubjetivo de justiça..........................23

1.2. A dinâmica do conflito

1.2.1. As etapas do conflito até a disputa (e daí por diante) ..................................27

1.2.2.A ampliação e a redução do conflito .............................................................33

1.2.3. Cada conflito é um caso .....................................................................................35

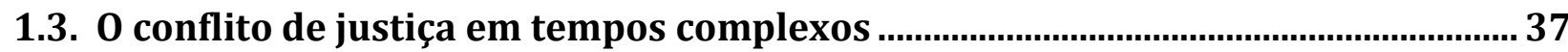

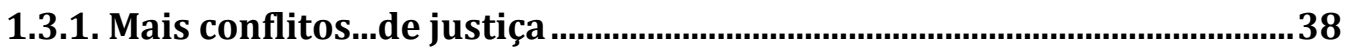

1.3.2. 0 conflito no ambiente do pluralismo jurídico............................................42

1.3.2.1. 0 direito dos livros e o direito em ação............................................................. 44

1.3.2.2. À sombra da lei ........................................................................................................ 46

1.3.3. Os campos sociais semiautônomos e a sociedade em rede ......................49

Síntese

CAPÍTULO 2. OLHANDO PARA OS LADOS: AS INSTITUIÇÕES E OS PROCESSOS

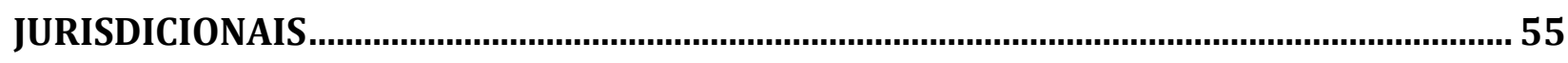

2.1. 0 redimensionamento do conceito de jurisdição .................................................. 58

2.1.1 A ausência do monopólio estatal da jurisdição ...........................................59

2.1.1.1. A jurisdição arbitral......................................................................................... 59

2.1.1.2. A jurisdição consensual................................................................................ 62

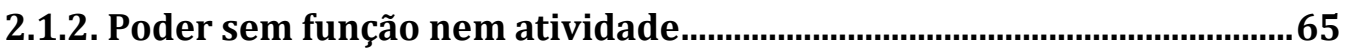

2.1.3. Duas questões da jurisdição como poder ..................................................68

2.1.3.1. A questão da normatividade informal .......................................................... 68 

2.1.3.2. A questão dos valores do procedimento.

2.1.4. A jurisdição como processo diferenciado da relação entre as partes. 73

2.1.5. Resumidamente: onde incide a jurisdição? ..................................................75

2.2. Instituições: processos decisórios e processos jurisdicionais

2.2.1. Instituições como feixe de processos decisórios ........................................79

2.2.2. A instituição e o processo decisório típico ...................................................82

2.2.3. Processos jurisdicionais: entre o acordo e a decisão .................................86

2.2.4. Uma proposta institucional comparada da jurisdição ...............................88

2.2.4.1. O processo jurisdicional em comparação com outros processos ............ 88

2.2.4.2. A comparação entre processos jurisdicionais ................................................ 90

2.2.5. Duas ressalvas para a análise institucional comparada...........................93

2.2.5.1. 0 movimento conjunto das instituições......................................................... 93

2.2.5.2. A competição entre instituições impuras ......................................................... 94

2.3. A adequação entre instituições e conflitos .............................................................. 98

2.3.1. Momento de atuação ….................................................................................. 98

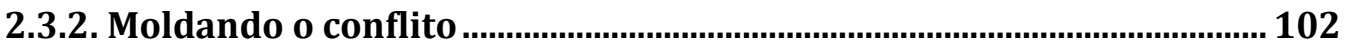

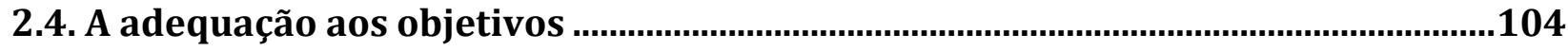

2.4.1. Entre a eficiência e a equidade ......................................................................... 107

2.4.2. Argumentos de qualidade e argumentos de quantidade ..................... 109

2.5. A emissão de sinais pelas instituições

2.5.1. Os efeitos irradiadores dos tribunais (e dos demais processos jurisdicionais)

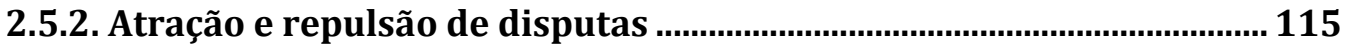

2.6. A dificuldade de transformar o processo típico

2.6.1. 0 processo judicial em sua matriz tradicional e o processo de interesse público 118

2.6.2. Rumo ao processo judicial da pacificação? 120

Síntese .123

CAPÍTULO 3. OBSERVANDO QUEM ESTÁ PRESENTE: AS PARTES EM AÇÃO

3.1. Partes em ação

3.1.1. Marc Galanter e o outro lado do telescópio 130

3.1.2. Neil Komesar e o modelo centrado na participação 132

3.1.3. Pontos em comum 138

3.1.3.1. Diálogo entre as obras .138

3.1.3.2. A irradiação de sinais. .139 

3.1.3.3. Jogadores habituais/ participantes eventuais e minoria concentrada/ maioria dispersa. . .140

3.1.3.4. Igualando as vantagens no processo judicial..............................................142

3.1.3.5. Resumo dos pontos em comum ..................................................................... 143

3.1.4. Vantagens do uso conjunto das teorias ....................................................... 144

3.1.4.1. Os que têm estão na frente em qualquer lugar ...........................................144

3.1.4.2. Os limites do processo judicial para corrigir tendências minoritárias 146

3.1.4.3. Análise antes e depois da situação indesejada .............................................147

3.1.4.4. Outra combinação possível: os efeitos da repetição ..................................148

3.1.4.5. A recepção desigual dos sinais...................................................................152

3.1.4.6. Subgrupos catalíticos na maioria dispersa ..............................................154

3.1.4.7. Relações informais como causa de vantagem?............................................157

3.2. Mais motivos para os que têm saírem na frente......................................................158

3.2.1. A interferência das partes sobre o conflito.......................................... 158

3.2.1.1. A escolha (racional?) do conflito.............................................................158

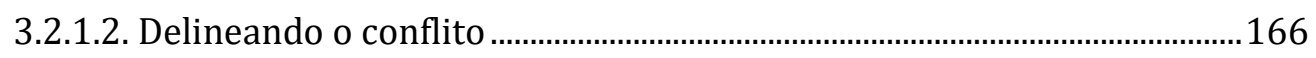

3.2.3. A interferência das partes nas instituições............................................ 168

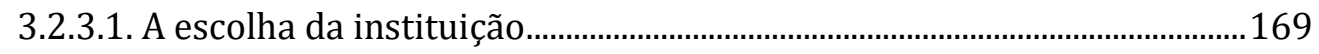

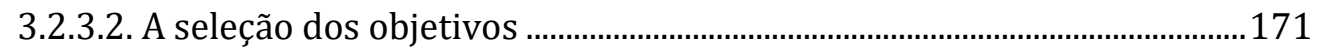

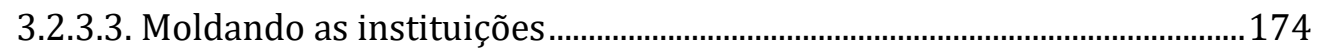

3.2.3.4. A internalização da lei e a criação do próprio campo de jogo ..................177

3.3. $\mathrm{E}$ as demais oposições entre as partes? .....................................................................184

3.4. Outros dois atores relevantes ..............................................................................186

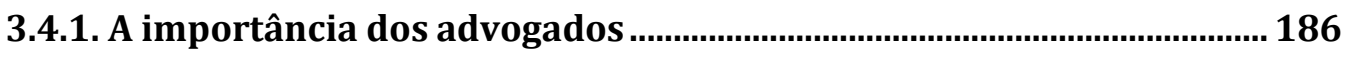

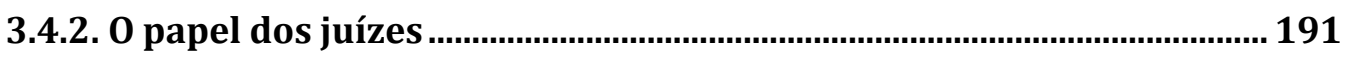

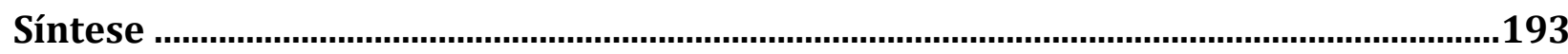

CAPÍTULO 4. E ENTÃO? A JUSTIÇA ENTRE 0 EXCESSO E 0 ACESSO ………......................195

4.1. Do acesso para o excesso …….........................................................................................196

4.2. 0 conflito como litígio judicial a ser eliminado ….......................................................200

4.2.1. Muitos processos judiciais e poucos conflitos no Judiciário?.............. 200

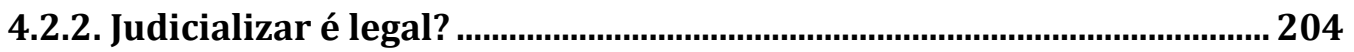

4.3. 0 Judiciário como única instituição que presta jurisdição ………………………......206

4.3.1. Os meios consensuais na Política Judiciária de tratamento adequado de conflitos. 

4.3.3. A compatibilidade da política de tratamento de conflitos com o processo judicial típico

4.3.4. A inserção da litigiosidade na agenda judicial..

4.4. A ignorância das partes

4.4.1. A judicialização excessiva e a sobrecarga de processo. 219

4.4.2. Tratando igualmente os desiguais?

4.4.3. A responsabilização do participante eventual pela litigiosidade excessiva

4.5. A retomada da pauta expansionista

4.5.1. 0 acesso à ordem jurídica justa sob a ótica da instrumentalidade metodológica 234

4.5.2. A inevitável questão alocativa 239

4.6. De novo, a análise institucional comparada

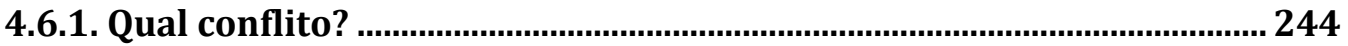

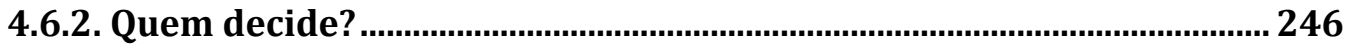

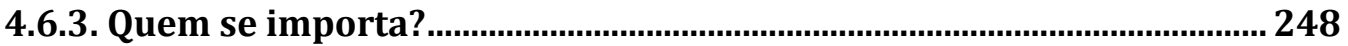

4.6.4. Um quadro de perguntas ........................................................................ 253

Síntese

CONCLUSÕES. 



\section{INTRODUÇÃO}

Cada vez mais se ouve falar que há no Brasil uma "explosão de litigiosidade", ${ }^{3}$ uma "inundação de ações", ${ }^{4}$ um "tsunami processual", ${ }^{5}$ uma "enxurrada" 6 ou uma "avalanche" 7 de processos, entre tantas outras expressões hiperbólicas. A construção desse cenário atemorizante é repleta de dados assustadores. Em especial, é corrente a análise que compara a quantidade de processos judiciais existentes no Brasil (cerca de 100 milhões) ${ }^{8}$ com o número da população brasileira (aproximadamente 200 milhões de habitantes $)^{9} \mathrm{e}$, após ponderar que há um processo para cada dois habitantes, chega à conclusão de que toda a sociedade brasileira é parte, na medida em que cada ação possui ao menos um autor e um réu.

Essa comparação não se restringe ao senso comum, invadindo as próprias decisões judiciais. No julgamento do Recurso Extraordinário nº 631.240/MG, em 03 de setembro de 2014, quando o Supremo Tribunal Federal (STF) consagrou a exigência do prévio requerimento administrativo para o ingresso de pedido judicial de benefício em face do Instituto Nacional do Seguro Social (INSS), o Ministro Gilmar Mendes ponderou

\footnotetext{
${ }^{3}$ ESTADO DE S. PAULO. Explosão de litigiosidade. Estado de S. Paulo, 18 set. 2010. Disponível em: https://bit.ly/2VhsGqi. Acesso em 28 dez. 2018. Obs.: para facilitar a leitura das notas de rodapé, utilizouse, como regra, um encurtador de URL ao se indicar fontes retiradas da internet. Os endereços completos originais, salvo indicação diversa, estão disponível na seção reservada às Referências, infra.

${ }^{4}$ Ao apontar que a ampliação do campo dos direitos pela Constituição de 1988 teria aumentado enormemente a quantidade de áreas sujeitas ao controle judicial, Bernardo Sorj afirma que, como consequência, o "STF foi literalmente inundado por milhares de ações que se acumulam" ( $A$ Nova Sociedade Brasileira. $3^{\mathrm{a}}$ ed. Rio de Janeiro: Jorge Zahar Editor, 2006, p.115-116).

${ }^{5}$ MANCUSO, Rodolfo de Camargo. Acesso à justiça: condicionantes legítimas e ilegítimas. $2^{\mathrm{a}}$ ed. São Paulo: Revista dos Tribunais, 2015, p.45.

${ }^{6}$ ESTADO DE S. PAULO. Aumento de litigiosidade compromete mecanismos processuais. Estado de S. Paulo, 28 dez. 2015. Disponível em: https://bit.ly/2Q6mAoH. Acesso em 28 dez. 2018.

${ }^{7}$ MANUS, Pedro Paulo Teixeira. Avalanche de processos atrasa bons julgamentos ou gera decisões sem cuidado. Consultor Jurídico, 03 fev. 2017. Disponível em: https://bit.ly/2EQeu2g. Acesso em 28 dez.. 2018.

${ }^{8}$ O Relatório Justiça em Números -2018, produzido pelo Conselho Nacional de Justiça, indica que, no anobase de 2017, houve o ingresso de 29,1 milhões de casos novos, foram baixados 31 milhões de processos e restaram 80,1 milhões de casos pendentes. A soma dos casos pendentes com os baixados atinge, então, mais de 100 milhões. Tal quantidade se mantém relativamente constante desde 2013 (Brasília: CNJ, 2018, p.7374).

${ }^{9}$ Para o ano de 2017, a projeção da população brasileira feita pelo Instituto Brasileiro de Geografia e Estatística (IBGE) foi de 207.660.929 (Brasil em Números. Vol. 26. Rio de Janeiro: IBGE, 2018, p. 88).
} 
em seu voto: 10 “O Brasil é um dos países com um dos maiores índices de judicialização. Estamos falando de 100 milhões de processos em tramitação. Portanto, estamos falando que, para cada dois habitantes, um tem uma demanda na Justiça”.

Na mesma linha, em seu discurso de posse como Presidente do STF, em 10 de setembro de 2014, o Ministro Ricardo Lewandowski" reafirmou o cenário de "explosão de litigiosidade", mencionando que a Constituição de 1988 "escancarou" as portas dos tribunais, "não apenas porque continuou a dar guarida ao consagrado princípio da inafastabilidade da jurisdição (...), como também porque colocou à disposição dos cidadãos vários novos instrumentos de acesso à Justiça, em especial as ações de natureza coletiva". Dados estatísticos relativos aos milhões de processos foram sobejamente citados. $^{12}$

Por sua vez, a Portaria do Conselho da Justiça Federal n ${ }^{\circ} 369$, de 10 de setembro de 2017, que dispõe sobre a instituição do Centro Nacional e Local de Inteligência da Justiça Federal, deixou expresso entre seus considerandos "que o crescimento acumulado de demandas desde 2009 foi de 19,4\% e que, 'mesmo que o Poder Judiciário fosse paralisado sem ingresso de novas demandas, com a atual produtividade de magistrados e servidores, seriam necessários aproximadamente 3 anos de trabalho para zerar o estoque", 13

Essa percepção da cúpula do Judiciário é propalada pela mídia, ${ }^{14}$ e, assim, atinge a população em geral. No entanto, questionar se e até que ponto a litigiosidade é excessiva, caso centrada somente no Judiciário, leva a uma discussão bizantina. Saber se os juízes

${ }^{10}$ É interessante observar como o argumento retórico de se dividir o número de ações pela população não se limita ao Brasil. Em fala publicada em 1986, o Presidente da Associação Nacional de Manufaturadores dos Estados Unidos já afirmava: "We're now the most litigious country on earth one of every fifteen Americans filed a private civil suit last year" (Cf. GALANTER, Marc. The Three-Legged Pig: Risk Redistribution and Antinomianism in American Legal Culture. Mississippi College Law Review, vol. 22, 2002-2003, p.53).

${ }^{11}$ Disponível em: https://bit.ly/2GLueFy. Acesso em 28 dez. 2018.

${ }^{12}$ Destaque-se o seguinte trecho:

Em 2013, segundo o último levantamento do Conselho Nacional de Justiça, tramitaram no Judiciário brasileiro cerca de 95 milhões processos. Naquele ano, foram ajuizados aproximadamente 28 milhões de casos novos, sem contar os feitos que ingressaram no Supremo Tribunal Federal.

Mediante um esforço quase sobre-humano os magistrados brasileiros - cujo número correspondia a aproximadamente 16.500 juízes - proferiram mais de 25 milhões sentenças, o que resultou numa média de cerca de 1.600 para cada um deles. Não obstante esse excepcional desempenho, a taxa de congestionamento processual continuou elevadíssima, chegando a quase $71 \%$ das ações em trâmite. Isso, em grande parte, porque temos hoje quase 6.500 cargos em aberto, correspondendo a mais de $39 \%$ do total de nosso efetivo de juízes, por motivos que vão desde a falta de verbas para preenchê-los até a carência de candidatos motivados ou qualificados.

O Supremo Tribunal Federal, à semelhança do que ocorreu com o Judiciário como um todo, também foi contemplado com uma extraordinária sobrecarga de trabalho no ano passado. Ao longo de 2013 foram distribuídos 44.170 processos aos seus onze ministros, que proferiram 85.000 decisões, das quais 72.167 monocráticas e 12.833 colegiadas. (idem).

${ }^{13}$ Posteriormente, tal Portaria foi referendada pela Resolução CJF n ${ }^{\circ} 499$, de $1^{\circ}$ de outubro de 2018, que, todavia, não repetiu esse motivo entre seus considerandos.

${ }^{14}$ Vide como exemplos as matérias citadas nas notas 3 e 6 , supra. 
estão ou não assoberbados de processos dependeria, no mínimo, da definição do que seria o volume suportável de trabalho. A diversidade de casos, a dificuldade em contrapor culturas diversas e a inexistência de dados consistentes para o levantamento de uma série histórica são apenas algumas das dificuldades.

Além disso, ainda que todas essas informações estivessem disponíveis, acredita-se que a questão principal permaneceria deslocada. Mais importante do que indagar se há processos em excesso é saber se os conflitos que estão sendo encaminhados para a via judicial deveriam sê-lo. De fato, se o Judiciário (e o processo judicial) for a instituição mais recomendada para o tratamento do conflito, a "explosão de litigiosidade" deveria ser comemorada em vez de lamentada.

Para que essa análise seja possível, é necessário proceder a uma comparação entre as opções disponíveis. Assim sendo, em vez de investigar se o Judiciário possui ou não muitas demandas, o que importa é responder à seguinte questão: dentre as instituições disponíveis, qual a mais adequada para o tratamento do conflito existente entre as partes?

A resposta a essa indagação, porém, exige considerar outra perspectiva, que gira em torno de três elementos: o conflito, as instituições e as partes. De fato, nota-se que, frequentemente, o Judiciário é tido como o foro exclusivo para o tratamento de conflitos, confundindo-se o que está judicializado com o conflito em geral. Além do mais, as partes, quando não são vistas sob o viés da relação de direito material, são consideradas como sujeitos processuais, o que minimiza a análise de suas características estruturais além do processo. Nessa linha de raciocínio, a análise da adequação muitas vezes fica restrita ao conflito (judicializado) entre partes (sujeitos processuais) no interior de um processo (judicial). Centrado no Judiciário, critica-se o excesso de processos judiciais sem analisar as opções ao redor ou as dinâmicas das partes envolvidas.

$\mathrm{Na}$ busca do processo mais adequado, o que este trabalho propõe é alterar o foco de análise, realizando, metaforicamente, três movimentos: dar um passo para trás (esbarrando no conflito em vez de ficar restrito ao litígio judicial), olhar para os lados (enxergando as diversas instituições e processos jurisdicionais sem se limitar no Judiciário) e observar quem está presente (percebendo as características estruturais das partes em ação).

Acredita-se que esses movimentos tanto servem como diagnóstico da insuficiência dos conceitos que sustentam o discurso da "explosão de litigiosidade" quanto como forma de tratamento para que o prognóstico seja favorável, isto é, para que seja empregado o 
processo mais adequado para o tratamento do conflito ou, em termos mais amplos, para a promoção da justiça.

Nesse contexto, por exemplo, se uma briga entre cônjuges é mais bem tratada na Vara de Família ou em uma Câmara Privada de Mediação depende da investigação do conflito, do modo como cada processo existente vai tratá-lo e das características das partes envolvidas. Também é relevante saber quais são os objetivos buscado pelos envolvidos, para, então, perquirir comparativamente qual instituição é mais propícia a atingi-los.

Em termos mais amplos, cabe perguntar: quais são as características do conflito em questão? Quais são as instituições ou processos disponíveis para o seu tratamento? Por quem e como tais instituições são acessadas? Isso é adequado para o quê? No contexto desses questionamentos, surge a hipótese central deste trabalho: a análise da dinâmica entre conflito, instituições e partes permite identificar parâmetros que auxiliam na escolha do processo mais adequado para o tratamento do conflito de acordo com as partes envolvidas e com os objetivos que se quer atingir, o que possibilita, como consequência, ver a imagem da "explosão de litigiosidade" sob outro ângulo.

Para o desenvolvimento dessa hipótese, cada um dos três movimentos é destacado em um capítulo. Neles, são trazidas algumas propostas conceituais que, para fins de auxiliar na compreensão, devem ser desde logo referidas.

Desse modo, dando um passo para trás, o primeiro capítulo trata do conflito antes de se tornar um litígio judicial. Para tanto, torna-se necessária uma ampliação conceitual do conflito, considerando-o como contraposição de movimentos e não apenas como oposição de interesses. O conflito, assim, surge a partir da percepção da contraposição, quando o sujeito se vê diante de uma situação indesejada. Se essa situação indesejada é tida como injusta, tem-se um conflito de justiça, não se limitando o justo aos parâmetros do direito estatal. Se o conflito de justiça é atribuído a outra pessoa, que possui percepção diversa do que seria justo, há o conflito intersubjetivo de justiça. Caso essa contraposição entre as partes seja encaminhada para um processo decisório que tenha como traço diferenciado justamente o tratamento de conflitos, surge a disputa. Disputa, desse modo, é o conflito tornado público mediante o encaminhamento para um processo decisório especialmente voltado para o seu tratamento.

Por sua vez, olhando para os lados, o segundo capítulo aponta a diversidade de alternativas existentes para o tratamento da disputa, ressaltando que, sobretudo no 
pluralismo jurídico da sociedade complexa atual, o Judiciário não é a única opção. Isso exige, porém, o redimensionamento do conceito de jurisdição, que, então, é conceituada como o poder de decidir imperativamente a disputa por meio de um processo - ou seja, um procedimento dotado de normatividade formal ou informal - que seja minimamente diferenciado da relação entre as partes. Os termos dessa equação são desenvolvidos no decorrer do capítulo, mas, de imediato, cabe notar que processo jurisdicional (isto é, que oferece jurisdição), não se limita ao processo judicial, podendo também existir também no âmbito de outras instituições. Em particular, são destacadas quatro instituições: a comunidade, o mercado, o processo político e o Judiciário. Instituições são tomadas, assim, como feixes de processos decisórios, dentre os quais os processos jurisdicionais. Cada instituição possui um ou mais processos típicos que, tal como em uma metonímia, frequentemente são confundidos com a própria instituição. Por isso, costuma se falar do processo judicial adjudicatório como se fosse o próprio Judiciário, olvidando-se que o Judiciário também possui opções de processos não adjudicatórios e, mesmo, não jurisdicionais. Esse mesmo raciocínio permite identificar opções jurisdicionais nas instituições que tenham processos decisórios não jurisdicionais como típicos. Notar as características das instituições e a dinâmica institucional permite, portanto, comparar os processos em busca daquele que seja mais adequado aos objetivos visados.

Conflitos e instituições, porém, são meras abstrações sem os agentes envolvidos no conflito e que, ao menos potencialmente, participam dos processos decisórios. Assim sendo, observando quem está presente, o terceiro capítulo destaca a importância de se investigar a dinâmica das partes em ação. $O$ conceito de parte, nesse contexto, não se reduz aos de envolvidos na relação de direito material ou de sujeitos processuais. Defende-se a necessidade de observar as características estruturais das partes no contexto fático em que estão inseridas, bem como perceber como tais características são transpostas quando de sua participação em um processo decisório. A desigualdade estrutural das partes pode, então, ser mitigada ou ampliada, dependendo do processo escolhido. Para destacar essa dinâmica, toma-se como base um caso em que o desequilíbrio é notório: a oposição entre a pobre pessoa física participante eventual (oneshotter) e o rico jogador habitual pessoa artificial (repeat player). Com isso, observa-se que o juízo de adequação não pode ignorar as partes em ação.

Em contrapartida, o quarto e último capítulo busca retomar os conceitos apresentados, analisando a ideia de "explosão de litigiosidade" em contraposição à expansão do acesso à justiça a partir dos parâmetros analíticos firmados nos capítulos 
anteriores. Sem pretender uma análise do complexo tema do acesso à justiça, limita-se a utilizá-lo para perceber como a lógica do excesso se fundamenta em concepções reducionistas do conflito, das instituições e das partes. Os três movimentos propostos, assim, servem para o diagnóstico do problema, ao mesmo tempo em que reforçam a necessidade de ir além das perguntas que normalmente são feitas. Em vez de questionar se há muitos processos judiciais, acredita-se que o relevante é saber se os processos que estão no Judiciário deveriam estar lá. Nesse segundo aspecto, procura-se apontar parâmetros para a busca do processo adequado, tanto para resolver a disputa como, em termos mais amplos, para alocar a justiça a ser oferecida. Tais parâmetros girariam, basicamente, em torno de três eixos, que são resumidos nas seguintes questões: Qual conflito? Quem decide? Quem se importa?

Em síntese, o trabalho volta-se ao estudo do conflito, das instituições e das partes para observar como esses elementos se apresentam e como interagem entre si, com o objetivo de contribuir para o estabelecimento de parâmetros que auxiliem na identificação do processo adequado, o que poderá contribuir também para uma
percepção mais crítica da ideia comumente difundida da "explosão da litigiosidade".

A proposta tenta se distinguir dos estudos processuais correntes acerca do juízo de adequação ao partir de uma perspectiva que não esteja restrita ao processo judicial ou, mesmo, à análise estritamente jurídica. Por sua vez, no âmbito dos estudos sociojurídicos no qual este trabalho pretende se inserir, ${ }^{15}$ a particularidade é a tentativa do tratamento conjunto dos conflitos, instituições e partes, em vez de se limitar a um só aspecto. ${ }^{16}$

\footnotetext{
15 Basicamente isso significa adotar premissas e valer-se da literatura do que, nos Estados Unidos, é conhecido como Law and Society (Direito e Sociedade). De acordo com Kitty Calavita, em vez de estudar o Direito dentro da caixa da sua lógica interna, o Direito e Sociedade toma exatamente o caminho inverso: examina as influências das forças externas à caixa (Invitation to Law \& Society: An Introduction to the Study of Real Law. 2 ed. Chicago: Chicago University Press, 2016, p.4.). No Brasil, muitas vezes essa corrente se aproxima do que vem sendo tratado como pesquisa empírica, embora não se reduza a ela. Como esclarece Fabio Sá e Silva: “(...) pode haver confusão com o tratamento do tema nos EUA, onde a principal sociedade científica constituída em torno de 'estudos empíricos em direito', a Society for Empirical Legal Studies (SELS), baseada na Escola de Direito da Universidade de Cornell, costuma atrair pesquisadores com abordagem mais quantitativa. A Law and Society Association (LSA) e a noção de pesquisa em Direito e Sociedade (Law and Society ou L\&S) parecem se aproximar mais do que se faz no Brasil a título de PED, embora também não seja possível estabelecer identidade entre L\&S e PED.”(Vetores, Desafios e Apostas possíveis na Pesquisa Empírica em Direito no Brasil. Revista de Estudos Empíricos em Direito, vol.3, nº 1 , 2016, p.27, nota 3). No entanto, a obra de Neil Komesar, ou seja, um autor que costuma ser associado à corrente do Law and Economics, também será amplamente utilizada. Os motivos para a utilização desse autor em específico parte da convicção de que é possível estabelecer um diálogo entre a sua obra e a perspectiva da Law and Society, como será explicitado adiante no corpo do texto.

${ }^{16}$ Ao fazerem um breve relato dos estudos acerca do surgimento das disputas, Lynn Mather e Barbara Yngvesson notam a tendência em se privilegiar um ou outro aspecto e não o conjunto (Disputes, Social
} 
A partir da breve menção aos capítulos do trabalho, já é possível vislumbrar a metodologia e os referenciais teóricos adotados. A abordagem sociojurídica leva ao uso de dados estatísticos e à consideração do Direito na realidade concreta. Embora não se ignorem tais fontes, este trabalho não procura realizar uma pesquisa empírica, sendo eminentemente teórico. O estudo baseia-se, sobretudo, na leitura bibliográfica.

Em especial, como referências, destacam-se as obras de três autores: Marc Galanter, Neil Komesar e Carlos Alberto de Salles. A escolha deles justifica-se pela compatibilidade de suas observações com os movimentos propostos na busca do processo adequado. Não se trata, porém, de conferir-lhes exclusividade sobre o tema, mas apenas de tomá-los como o instrumental teórico que se entende mais apropriado para as finalidades escolhidas.

É certo que Galanter é mais associado aos estudos sociojurídicos (Law \& Society), ao passo que Komesar é relacionado à análise econômica do direito (Law \& Economics), sob a vertente da análise institucional comparada (comparative institutional analysis). Dado esse aparente distanciamento, os pontos em comuns das teorias e as potencialidades do uso conjunto serão detalhadas no decorrer do trabalho, em especial no capítulo 3.

Por ora, basta mencionar que o modo analítico de Galanter, em geral, baseia-se na percuciente análise da realidade fática em busca de padrões, mas sem a pretensão de criar propriamente um modelo teórico. ${ }^{17}$ Seu famoso artigo Why the "Haves" Come out Ahead: Speculations on the Limits of Legal Change, ${ }^{18}$ em larga medida adotado neste trabalho, pode ser interpretado como o resultado de um raciocínio indutivo do cenário norte-americano, que o levou à identificação das categorias dos repeat players e dos oneshotters. A utilização de tal artigo como referencial teórico ou a tentativa de replicar a oposição entre os dois tipos de litigantes para outros contextos pode, por isso, gerar ruídos, justamente porque não se buscou construir um modelo teórico. Como exemplo de ruído, basta citar a indevida aproximação entre repeat players e a litigiosidade repetitiva no Brasil. A ideia de repetição considerada por Galanter (estar frequentemente em juízo) não se confunde com se envolver repetidamente com os mesmos tipos de litígios. ${ }^{19}$

Construction and Transformation of. In: WRIGHT, James (ed.). International Encyclopedia of the Social \& Behavioral Sciences, vol. 6. 2a ed. Amsterdam: Elvesier, 2015, p.561-562).

${ }^{17}$ Este argumento baseia-se na observação de Carlos Alberto de Salles durante o ano de 2018, quando da construção da tese.

${ }^{18}$ Law and Society Review, 1974, vol. 9, $\mathrm{n}^{\mathrm{o}}$ 1, p.95-160.

${ }^{19}$ Como esclarece Paulo Eduardo Alves da Silva: "o 'litigante repetitivo' de Galanter não tem o mesmo sentido que a nossa 'litigiosidade repetitiva'. Aquele é o litigante que participa de muitos processos 
Por sua vez, o que Komesar ambiciona é fornecer um modelo teórico consistente capaz de modificar a própria forma de interpretar o Direito nas suas diferentes áreas. Komesar, inclusive, defende a necessidade de o ensino e o discurso jurídicos serem modificados de modo a se reconhecer a importância da análise institucional comparada. ${ }^{20}$ O uso de conceitos como instituições, modelo centrado na participação, tendências majoritárias e minoritárias (duas forças), entre outros, ${ }^{21}$ visa à generalização e não simplesmente ao relato da realidade subjacente. Ademais, embora Komesar admita expressamente que sua obra se relaciona a Law \& Economics, deixa também claro que não se restringe a ela, pois qualquer análise da lei e de política pública - seja ou não econômica, dependeria da análise institucional comparada. ${ }^{22}$

Desse modo, a abstração teórica de Komesar, em conjunto com as observações indutivas de Galanter, pode contribuir reciprocamente para a análise do contexto brasileiro, em especial no que se refere ao tema da busca do processo adequado. Essa aproximação entre Komesar e Galanter não é novidade no âmbito dos estudos processuais no Brasil, sendo realizado, sobretudo, na obra de Carlos Alberto de Salles. ${ }^{23}$ De fato,

judiciais; essa é o fenômeno de haver vários litígios sobre uma mesma questão geralmente jurídica. Na litigiosidade repetitiva há, é verdade, um litigante repetitivo: as empresas de telecomunicações e os bancos nos litígios de consumo; o governo nos litígios previdenciários e execuções fiscais. Mas os fenômenos não se identificam principalmente por conta da perspectiva com que olhamos para cada fenômeno. Galanter (1974) está preocupado com a justiça que o sistema produz, o que faz com que ele identifique um foco de desigualdade (portanto, injustiça) nas vantagens do litigante repetitivo. $O$ debate sobre litigiosidade repetitiva no Brasil, cujas conclusões foram acolhidas pelo legislador processual civil, está preocupado com o volume de processos nos tribunais, o que induz a crer que o proponente das ações judiciais, , que geralmente é o 'participante eventual', não o 'jogador habitual', seria responsável pela aumento da litigiosidade.” (Acesso à justiça, litigiosidade e o modelo processual civil brasileiro. Tese de LivreDocência. Ribeirão Preto: Faculdade de Direito de Ribeirão Preto, Universidade de São Paulo, 2018, p.57, nota 73).

${ }^{20}$ Essas mudanças são defendidas por Komesar em Law's Limits: Rule of Law and the Supply and Demand of Rights. New York: Cambridge University Press, 2001, p.174-180.

${ }^{21} \mathrm{O}$ conceito de instituição, de acordo com a teoria de Komesar, será explicitado, sobretudo, no Capítulo 2. A ideia de modelo centrado na participação e duas forças é destacada, em especial, no Capítulo 3.

${ }^{22}$ Como afirma Komesar: “(...) any analysis of law and public policy - economic or not - depends on comparative institutional analysis. Institutional choice is the necessary connection between any social goal or goals and law and public policy" (Imperfect Alternatives: Choosing Institutions in Law, Economics and Public Policy. Chicago: University of Chicago, 1994, p.10). De todo modo, mesmo a associação mais simplista de Galanter com a corrente da Law \& Society e de Komesar com a Law \& Economics não impediriam sua aplicação conjunta, na medida em que os achados empíricos mais bem cuidados de uma corrente poderiam ser enriquecidos com os modelos teóricos rigorosos da outra e vice-versa. Nesse sentido, defendendo a possibilidade do uso conjunto da sociologia do direito e da análise econômica do direito, vide FIX-FIERRO, Héctor. Courts, Justice \& Efficiency: A Social-Legal Study of Economic Rationality in Adjudication. Portland: Hart Publishing, 2003, 61-62.

${ }^{23}$ Em especial, o uso conjunto das contribuições de Galanter e Komesar fica visível em: SALLES, Carlos Alberto de. Execução Judicial em Matéria Ambiental. São Paulo: Revista dos Tribunais, 1998. As obras de Galanter e Komesar, porém, também contribuem para a análise e são referidos em: SALLES, Carlos Alberto de. Arbitragem em Contratos Administrativos. Rio de Janeiro: Forense, 2011. 
Salles faz a devida contextualização de Galanter e Komesar para o cenário do direito processual pátrio, o que é de suma importância para a aproximação pretendida neste trabalho.

O uso da obra de Salles justifica-se, assim, pela identidade das fontes e das consequentes premissas teóricas adotadas. Além disso, ao propor a radicalização da ideia do processo como instrumento para realização de objetivos a ele externos, o que exige colocar a realidade fática e os problemas de cada campo específico do direito como ponto de partida ${ }^{24}$ o conceito de instrumentalidade metodológica é a principal justificativa para que, ao se perquirir acerca da adequação, não se limite à análise do processo judicial. À luz da instrumentalidade metodológica, é necessário dar um passo para trás em direção ao conflito, olhar para o lado vendo as instituições e observar quais são as partes presentes.

${ }^{24}$ Arbitragem em Contratos Administrativos, cit., em especial, p.13-27. 


\section{CONCLUSÕES}

\begin{abstract}
"nenhuma instituição humana é perfeita - seja uma agência governamental, um negócio de sucesso, uma grandiosa universidade ou, em tal sentido, uma família. Se você quer uma instituição perfeita, vá visitar uma colmeia ou um formigueiro."
\end{abstract}

- Richard Posner ${ }^{680}$

Na busca pelo processo adequado para o tratamento do conflito, o que se sugere, em síntese, é que se comece a procurar em outro lugar. Esta perspectiva diversa, baseada na instrumentalidade metodológica, envolve três movimentos: dar um passo atrás, indo do litígio judicial para o conflito; olhar para os lados, vendo as diversas instituições (processos decisórios) disponíveis além do Judiciário; e observar quem está presente, notando a dinâmica das partes em ação. Cada um desses movimentos implica uma série de desdobramentos conceituais, alguns dos quais foram abordados neste trabalho.

1.Desse modo, para se dar um passo atrás (Capítulo 1), torna-se necessário, em primeiro lugar, partir da definição ampla de conflito como contraposição de movimentos (item 1.1.1.1.), em vez da clássica definição carneluttiana baseada na contraposição de interesses (item 1.1.1.2). Na comparação dos conceitos (item 1.1.1.3), observa-se que a definição ampla adotada não exclui a mais restrita, sendo ainda útil para se perceber que o conflito não necessariamente é negativo e nem sempre deve ser resolvido de modo competitivo.

Diante da extensão do conceito adotado, porém, é necessário fazer um recorte para delimitar os conflitos que interessam ao Direito. Para tanto, com base no conceito de

${ }^{680}$ Divergent Paths: the Academy and the Judiciary. Livro eletrônico. Cambridge: Harvard University Press, 2016, p.74, em tradução livre. 
Antonio Rodrigues de Freitas Jr., foca-se no conflito de justiça, ou seja, aquele que se baseia na percepção de que a situação indesejada é também injusta (item 1.1.2).

Conflito de justiça e disputa, porém, não se confundem. De fato, o percurso é longo da nomeação do conflito como sendo de justiça, até a responsabilização de outra pessoa e subsequente reivindicação que, se negada e encaminhada para um processo jurisdicional, torna-se uma disputa (item 1.2.1). Ao subir os degraus da pirâmide da disputa, não apenas conflitos se perdem no caminho, como também podem sofrer reduções e ampliações que modificam suas características (item 1.2.2). Como o percurso e as mudanças sofridas no caminho invariavelmente são diversos, cada conflito vai ter sua própria história de vida (item 1.2.3).

No contexto da sociedade complexa atual, o que se nota é que mais conflitos são nomeados como de justiça (item 1.3.1). Dentro da perspectiva do pluralismo jurídico, é necessário observar, todavia, que o justo não é somente aquilo considerado como tal pelo direito estatal (item 1.3.2). De igual modo, a oposição entre direito dos livros e direito em ação (item 1.3.2.1), bem como a noção de sombra da lei (item 1.3.2.2), devem ser interpretadas à luz do pluralismo jurídico. Na modernidade, destaca-se ainda que o pluralismo não se configura simplesmente pela existência de diferentes ordenamentos jurídicos, mas também pela intensa comunicação existente entre eles, formando campos sociais semiautônomos numa sociedade em rede (item 1.3.3). Nesse ambiente, a diversidade de conflitos, baseados em diferentes concepções do justo, implica, inclusive, a existência de diversos processos voltados ao seu tratamento.

2. De maneira a perceber a multiplicidade de processos aptos à solução de controvérsias, é importante, então, olhar para os lados e ver as instituições disponíveis além do Judiciário (Capítulo 2). Isso exige, porém, um redimensionamento do conceito de jurisdição, de maneira que a ausência do monopólio estatal seja reforçada (item 2.1.1), admitindo-se, entre outras, a jurisdição arbitral (item 2.1.1.1) e a jurisdição consensual (item 2.1.1.2). Com base em Carlos Alberto de Salles, afastam-se os elementos função e atividade do conceito de jurisdição, definindo-a como o poder de decidir imperativamente a disputa decorrente de um conflito intersubjetivo de justiça por meio de procedimento dotado de normatividade (item 2.1.2). Condizente com as premissas expostas no capítulo anterior, essa normatividade não se limita às normas positivadas, podendo, assim, ser informal (item 2.1.3.1), desde que seja, no mínimo, aceita pelo direito estatal (item 2.1.3.2). O que caracteriza o processo jurisdicional, então, não é a instituição a que 
pertence, mas sim o fato de ser especialmente voltado para o tratamento de disputas (item 2.1.4). Processo jurisdicional, portanto, é mais amplo que processo judicial (item 2.1.5).

No entanto, se o Judiciário não é o único que presta jurisdição, torna-se imprescindível perquirir acerca das outras instituições (item 2.2). Tendo como base o conceito de Neil Komesar, considera-se que existem quatro grandes instituições: a comunidade, o mercado, o processo político e o Judiciário. Cada uma delas é um feixe de processos decisórios (item 2.2.1), dentre os quais um ou mais seria o processo típico, identificando-se, tal como uma metonímia, com a própria instituição (item 2.2.2). Nesse sentido, se o processo de solução de disputas (isto é, jurisdicional) é o típico do Judiciário, isso não significa que ele não possa aparecer, ainda que como forma atípica, nas demais instituições (como, por exemplo, o uso da arbitragem comercial no âmbito do mercado). Dentre as diversas formas de classificar os processos jurisdicionais, destaca-se aquele que se baseia na finalidade visada, seja o acordo, seja a decisão (item 2.2.3).

Tais conceitos levam a uma proposta de análise institucional comparada da jurisdição (item 2.2.4). Assim, é possível comparar tanto o processo jurisdicional com outros processos decisórios não voltados ao tratamento de disputas (item 2.2.4.1), como também realizar uma comparação entre processos jurisdicionais (item 2.2.4.2). Nessas comparações, porém, deve-se ter a cautela de comparar situações de idêntica complexidade, para não confrontar o melhor cenário de um processo com o pior de outro (item 2.2.5.1). Além disso, cabe observar que, na realidade fática, frequentemente as instituições não se apresentam em sua forma pura e muito menos convivem de forma harmônica. Combinações entre processos de uma mesma instituição e entre processos de instituições diversas são corriqueiras (item 2.2.5.2).

Outrossim, é importante notar que os processos decisórios das instituições podem atuar em diferentes etapas do conflito, inclusive no momento prévio que envolve a escolha do próprio conflito (item 2.3.1). Destaque-se ainda que, ao tratarem o conflito, as instituições o modificam, o que pode incluir, por exemplo, a redução dos fatos em categorias legais e a denegação da subjetividade autêntica das pessoas envolvidas (item 2.3.2).

A busca do processo adequado, contudo, não se limita ao reconhecimento das suas características e da instituição que integra. É necessário perguntar para quê o processo é adequado. Nesse contexto, é relevante saber qual é o objetivo visado (item 2.4). É possível, hipoteticamente, ter como objetivo a eficiência ou a equidade (item 2.4.1) e, para tanto, valer-se de processos baseados em argumentos de qualidade ou de quantidade 
(item 2.4.2). A noção de processo adequado, logo, vai depender de onde se quer chegar, sob pena de ter como resposta que qualquer caminho serve.

Sob outro ângulo, se a proposta é de encontrar o processo adequado à luz da realidade fática, não se pode ignorar o movimento das instituições, ou seja, sua dinâmica. Em relação a esse aspecto, salienta-se que todas as instituições emitem sinais (item 2.5), o que, então, também se aplica ao Judiciário e aos demais processos jurisdicionais (item 2.5.1). Tais sinais, dentre outros efeitos, podem levar à atração ou a repulsão de disputas para determinada instituição (item 2.5.2). Além disso, aponta-se que as instituições podem sofrer transformações no decorrer de sua existência, a depender do contexto em que inseridas. A velocidade e a complexidade dessas transformações também são variáveis, acreditando-se, porém, que alterações estruturais no processo institucional típico sejam mais difíceis e demoradas (item 2.6). Como exemplos, cite-se a dificuldade de se atingir na plenitude um processo judicial de interesse público (item 2.6.1) ou aquele qualitativamente voltado à pacificação (item 2.6.2).

3. Ao passo que perceber a dinâmica dos processos é importante para o juízo de adequação, e sendo as instituições reativas por definição, resta observar quem está presente, ou seja, as partes em ação (Capítulo 3). Nessa análise, descabe considerar as partes apenas como sujeitos de direito ou sujeitos processuais. Para tanto, duas abordagens que se concentram na dinâmica das partes são especialmente úteis: seja olhando pelo outro lado do telescópio para enxergar a oposição típica entre o rico jogador habitual pessoa artificial (repeat players) e a pobre pessoa natural participante eventual (one-shotters), como faz Marc Galanter (item 3.1.1); seja centrando seu modelo na participação para aferir que os valores em jogo (stakes) podem ser distribuídos de maneira desigual entre as partes, como faz Neil Komesar (item 3.1.2).

De fato, as obras de Galanter e Komesar dialogam entre si (item 3.1.3.1). Ambos indicam a emissão de sinais pelas instituições (item 3.1.3.2); percebem a disparidade de interesses em jogo que existe entre litigantes habituais e participantes eventuais (item 3.1.3.3); e propõem formas de equalização das partes por meio do processo judicial (item 3.1.3.4). Os pontos comuns (item 3.1.3.5), então, confirmam a possibilidade do uso conjunto das teorias.

O uso conjunto permite, ainda, que uma teoria complemente a outra. Dessa forma, observa-se que os jogadores habituais de Galanter estão na frente em qualquer lugar e não somente no processo judicial (item 3.1.4.1). Além disso, se a oposição entre repeat 
players e one-shotters identifica-se como um caso de tendência minoritária, aplica-se a observação de Komesar de que o processo judicial não costuma ser tão apto para corrigir esse tipo de desvio (item 3.1.4.2). A análise da tipologia de Galanter, aliás, é enriquecida com a análise realizada a partir da distribuição de stakes entre as partes antes e depois da situação indesejada, tal qual proposta por Komesar (item 3.1.4.3). Em contrapartida, os efeitos da repetição notados por Galanter fazem com que uma nova distribuição de stakes seja considerada como relevante (item 3.1.4.4). Ademais, se os valores em jogo são distribuídos de maneira diversa, bem como se os custos da participação variam, então não surpreende que os sinais emitidos pelas instituições também sejam recebidos de modo desigual (item 3.1.4.5). Outra interpretação conjunta das teorias de Galanter e Komesar permite notar subgrupos catalíticos na maioria dispersa e que, em princípio, poderiam servir como alternativa à equiparação do one-shotter ao repeat player (item 3.1.4.6). Com fundamento em Komesar, é possível observar também que o privilégio de determinado grupo de interesses não decorre meramente por conta de relações informais facilitadoras com agentes do sistema de justiça como aponta Galanter, mas pode existir como simples decorrência da maior participação do grupo, independentemente da proximidade com o agente público e do comportamento esperado dele (item 3.1.4.7).

Em acréscimo, partindo da relação das partes com o conflito e com as instituições, observam-se ainda mais motivos para os jogadores habituais saírem na frente. Em relação à interferência das partes sobre o conflito (item 3.2.1), nota-se que os jogadores habituais pessoas artificiais podem avaliar mais racionalmente suas escolhas que as pessoas naturais participantes eventuais (item 3.2.1.1). Além disso, a própria forma como o conflito é delineado, como a seleção dos fatos pertinentes ou a forma narrativa mais apropriada, tendem a sofrer forte influência do repeat player e, dessa forma, a favorecê-lo (item 3.2.1.2). Por sua vez, no que se refere à interferência das partes nas instituições (processos decisórios) (item 3.2.3), tem-se que o jogador habitual possui maiores condições que o participante eventual de escolher a instituição em que pretende participar (item 3.2.3.1) e também de selecionar os objetivos a serem atingidos (item 3.2.3.2), moldando, assim, as próprias características dos processos, incluindo os jurisdicionais (item 3.2.3.3). Em certas situações, o repeat player chega, inclusive, a criar o próprio campo de jogo no qual as disputas serão resolvidas (item 3.2.3.4).

Dessa forma, a análise de uma situação extrema de distribuição desigual de stakes, caracterizando uma tendência minoritária, permite explicitar a importância de se analisar a dinâmica das partes na busca do processo adequado (item 3.3). Processo adequado, 
nesse sentido, é aquele que pode melhor traduzir a participação das partes, mitigando eventual desequilíbrio existente, e, assim, atingir o objetivo social comum a elas.

Por fim, cabe notar que há outros atores envolvidos na construção do processo decisório (item 3.4). Em especial, destacam-se dois deles: o advogado, que atua como ponte entre a situação fática das partes e o sistema estatal, mas também, em certas ocasiões, podem ser repeat players que almejam interesses próprios (item 3.4.1); e o juiz, que delimita qual instituição responsável pela decisão, mas igualmente, em alguns contextos, pode assumir o papel de jogador habitual dotado de pautas e agendas próprias (item 3.4.2).

4. Conflitos, instituições (processos decisórios) e partes, portanto, devem ser analisados a partir de uma perspectiva mais ampla que considere os fatores enumerados acima. Para corroborar a importância dessa forma de análise, cita-se como exemplo a noção de "explosão de litigiosidade", associando-a à lógica do excesso de justiça em detrimento da expansão do acesso (Capítulo 4). Nesse aspecto, a investigação proposta serve como diagnóstico e como forma de tratamento para que o prognóstico seja favorável.

Como diagnóstico, observa-se que, nos últimos anos, a lógica do excesso vem ganhando força em detrimento da lógica do acesso (item 4.1). A conclusão de que a questão de aceder à justiça estaria resolvida, cabendo agora lidar com o excesso, baseia-se em reduções em cada um dos três elementos destacados. Os conflitos são reduzidos aos processos judiciais, olvidando-se que poucos se tornam disputas (item 4.2.1). Além disso, destaca-se somente o aspecto negativo do conflito que, assim, deve ser eliminado o quanto antes (item 4.2.2). Por sua vez, o Judiciário é apontado como a única instituição que fornece jurisdição (item 4.3), o que se traduz em uma política estatista em relação aos meios consensuais (item 4.3.1), mas que, diante da lógica do excesso, é voltada à eliminação do acervo (item 4.3.2). Isso, de todo modo, não exige uma alteração substancial do processo judicial típico (item 4.3.3) e insere-se sem maiores dificuldades na agenda judicial acerca da litigiosidade, de natureza eficientista (item 4.3.4). Já as características estruturais das partes são frequentemente ignoradas (item 4.4). Nesse contexto, afirmações acerca da judicialização excessiva e da sobrecarga de processos (item 4.4.1), bem como a busca por soluções padronizadoras (item 4.4.2), tendem a prejudicar aqueles que possuem maiores dificuldades de acesso. Do mesmo modo, a 
responsabilização das partes pelo excesso pode esconder, no fundo, a velada atribuição de culpa ao participante eventual (item 4.4.3).

Em contrapartida, como forma de tratamento, os três movimentos propostos visam contribuir para a retomada da pauta expansionista do acesso à justiça. Para tanto, cabe considerar o acesso à ordem jurídica justa sob a ótica da instrumentalidade metodológica, indo além do Judiciário e não se limitando à justiça baseada no direito material (item 4.5.1). A expansão, todavia, não é ilimitada: como direito social, acessar à justiça necessariamente impõe uma inevitável questão alocativa (item 4.5.2).

Nesse aspecto, reitera-se que o discurso da "explosão de litigiosidade" parte de uma pergunta deslocada. Mais relevante do que descobrir se existem muitos processos no Judiciário, é saber qual a instituição (e qual o processo) que melhor serve para a concretização da justiça. Novamente, então, destaca-se a análise institucional comparada (item 4.6). Na busca pelo processo adequado para a promoção da justiça, valhe-se de uma análise semelhante àquela proposta para encontrar o processo jurisdicional adequado. De fato, processos jurisdicionais podem ser vistos como alternativas disponíveis entre os processos voltados ao acesso à justiça. Os três eixos de perguntas, então, são idênticos: Qual é o conflito (item 4.6.1)? Quem decide (item 4.6.2)? Quem se importa (item 4.6.3)? Tais perguntas implicam outras que, em conjunto, ajudam na busca e na comparação dos processos decisórios disponíveis (item 4.6.4).

O resumo das principais ideias apresentadas no decorrer do trabalho confirmam a tese de que o estudo do conflito, das instituições e das partes a partir de uma perspectiva mais ampla pode ser útil no estabelecimento de parâmetros que auxiliem na identificação do processo adequado. Isso também permite uma percepção mais crítica da ideia comumente difundida da "explosão da litigiosidade".

Destacou-se a importância de dar um passo atrás em direção ao conflito, olhar para o lado para as instituições e observar quais são as partes presentes. No entanto, se houve a tentativa de apontar, sob o aspecto conceitual, os movimentos que se entende como necessários para a busca do processo adequado, não houve uma preocupação em analisar determinado conflito, olhar comparativamente para as opções institucionais disponíveis na situação em concreto e observar as características reais dos sujeitos envolvidos. Restringiu-se ao exemplo "explosão de litigiosidade" para se enfatizar a importância dos movimentos identificados na busca do processo adequado. Do mesmo modo, a complexidade de cada um dos movimentos identificados impôs seleções acerca 
das características a serem abordadas. Não se chegou, por exemplo, ao conceito de conflito social e muito menos ao envolvimento de movimentos sociais; movimentos de desjudicialização e deslegalização foram citados, mas não aprofundados; a dinâmica das partes reduziu-se, basicamente, à análise de uma tipologia das partes, sem tratar das nuances existentes entre uma e outra ponta do continuum; etc. Tais abordagens poderão ser objeto de pesquisas futuras. Ao menos neste momento, porém, caminhar em direção a esses outros temas, talvez seria dar um passo maior que a perna. 


\section{REFERÊNCIAS}

ABEL, Richard L. A comparative theory of dispute institutions in society. Law \& Society Review, vol. 8, no 2, 1973, p.217-347.

ALBISTON, Catherine R.; SANDEFUR, Rebecca L.. Expanding the Empirical Study of Access to Justice. Wisconsin Law Review, 2013, p.101-120.

ALBISTON, Catherine; EDELMAN, Lauren B.; MILLIGAN, Joy. The Dispute Tree and the Legal Forest. Annual Review of Law and Social Science, vol.10, 2014, p.106-131.

ALEXANDER, Jeffrey C. The Meanings os Social Life: A Cultural Sociology. Livro Eletrônico. New York: Oxford University Press, 2003.

ALMEIDA, Ananda Palazzin de. A Atuação do INSS como Litigante Habitual no Recurso Extraordinário $n^{o}$ 631.240. Monografia de Especialização. São Paulo: Fundação Getúlio Vargas, Escola de Direito de São Paulo, 2015.

ALMEIDA, Diogo Assumpção Rezende de; PANTOJA, Fernanda Medina; ANDRADE, Juliana Loss de. Fundamentos. In: HALE, Durval; PINHO, Humberto Dalla Bernardina de; CABRAL, Trícia Navarro Xavier (org.). O Marco Legal da Mediação no Brasil: Comentários à Lei no 13.140, de 26 de junho de 2015. São Paulo: Atlas, 2016, p.35-90.

ALVES, Adler Anaximandro de Cruz e. A atuação cidadã da AGU na redução da litigiosidade envolvendo o Instituto Nacional do Seguro Social: considerações acerca de instrumentos de ação da AGU capazes de promover o amplo reconhecimento de direitos sociais. In: Publicações da Escola da AGU: Trabalhos Vencedores do Concurso de Monografias da AGU em 2009-2010. Brasília: EAGU, Brasília: EAGU, ano IV, nº 15, 2012, p.7-44.

ASSOCIAÇÃO BRASILEIRA DE JURIMETRIA. Os Maiores Litigantes da Justiça Consumerista: Mapeamento e Proposições. Brasília: Conselho Nacional de Justiça, 2017.

ASPERTI, Maria Cecília de Araujo. A Agregação Informal de Demandas Repetitivas na Conciliação Judicial: Pautas Concentradas e Mutirões. In: GABBAY, Daniela Monteiro; TAKAHASHI, Bruno (coord.). Justiça Federal: Inovações nos Mecanismos Consensuais de Solução de Conflitos. Brasília: Gazeta Jurídica, 2014, p.253-273.

Litigiosidade Repetitiva e a Padronização Decisória: entre o Acesso à Justiça e a Eficiência do Judiciário. Revista de Processo, vol. 263, jan.2017, p.233-255.

ASSOCIAÇÃO DOS MAGISTRADOS BRASILEIROS. O Uso da Justiça e o Litígio no Brasil. Brasília: AMB, 2015.

AZEVEDO, André Gomma de (org.). Manual de Mediação Judicial. $6^{\text {a }}$ ed. Brasília: Conselho Nacional de Justiça, 2016.

BACELLAR, Roberto Portugal. Mediação e Arbitragem. São Paulo: Saraiva, 2012. 
BADIN, Arthur Sanchez. Controle Judicial das Políticas Públicas: Contribuição ao estudo do tema da judicialização da política pela abordagem da análise institucional comparada de Neil K. Komesar. Dissertação de Mestrado. São Paulo: Faculdade de Direito da Universidade de São Paulo, 2011.

BAKHTIN, Mikhail (V. N. Volochínov). Marxismo e Filosofia da Linguagem. 9a ed. Tradução de Michel Lahud e Yara Frateschi Vieira com a colaboração de Lúcia Teixeira Wisnik e Carlos Henrique D. Chagas Cruz. São Paulo: Hucitec, 1999.

BANDEIRA, Regina. Conciliação antes do processo contribui para desafogar a Justiça. Conselho Nacional de Justiça, 10 abr. 2017. Disponível em: https://bit.ly/2RjLvtt [http://www.cnj.jus.br/noticias/cnj/84612-conciliacao-antes-do-processo-contribui-paradesafogar-a-justical. Acesso em: 28 dez. 2018.

BERCOVITCH, Jacob. Social Conflicts and Third Parties: Strategies of Conflict Resolution. Boulder: Westview, 1984.

BERCOVITCH, Jacob; KREMENYUK, Victor; ZARTMAN, I. William. Introduction: The Nature of Conflict and Conflict Resolution. In: BERCOVITCH, Jacob; KREMENYUK, Victor; ZARTMAN, I. William (ed.) The SAGE Handbook of Conflict Resolution. Los Angeles/London/New Delhi/Singapore/Washington D.C.: SAGE, 2009, p.1-11.

BERMAN, Paul Schiff. The New Legal Pluralism. Annual Review of Law and Social Science, vol.5, 2009, p.225-242.

BODART, Bruno. Seria a litigância uma questão de cultura? 15 jun. 2017. Disponível em: https://bit.ly/2SnME0z [https://abde.com.br/publicacoes/seria-a-litigancia-umaquestao-de-cultura-23]. Acesso em: 28 dez. 2018.

CALAMANDREI, Piero. Il Concetto di "Lite" nel Pensiero di Francesco Carnelutti. Rivista di Diritto Processuale Civile, vol. V, parte I. Padova: CEDAM, 1928, p.89-98.

CALAVITA, Kitty. Invitation to Law \& Society: An Introduction to the Study of Real Law. 2 ed. Chicago: Chicago University Press, 2016.

CAMPILONGO, Celso Fernandes. Política, sistema jurídico e decisão judicial. Livro Eletrônico. $2^{a}$ ed. São Paulo: Saraiva, 2011.

CAPPELLETTI, Mauro; GARTH, Bryant. Acesso à Justiça. Tradução de Ellen Gracie Northfleet. Porto Alegre, Sergio Antonio Fabris Editor, 1988.

CARAÇA, Ricardo Régener. Mediar é Divino - origens, histórico e relações do projeto do Judiciário goiano com a mediação e a conciliação no Direito Canônico. Tese de Láurea. São Paulo: Universidade de São Paulo, 2018.

CARAZZAI, Estelita Hass. Magistrados entram com dezenas de ações contra jornalistas no PR. Folha de S. Paulo, 07 jun. 2016. Disponível em:https://bit.ly/2N3w2Yk 
[https://www1.folha.uol.com.br/poder/2016/06/1778916-magistrados-entram-comdezenas-de-acoes-contra-jornalistas-no-pr.shtml] .Acesso em: 28 dez. 2018.

CARMONA, Carlos Alberto. Arbitragem e Jurisdição. Revista de Processo, vol.58, abril./jun. 1990, p. 33-40.

CARNELUTTI, Francesco. Como se Faz um Processo. Tradução de Hiltomar Martins de Oliveira. Belo Horizonte: Líder, 2005.

Sistema di Diritto Processuale Civile. Vol. I. Padova: CEDAM, 1936.

CARVALHO, Daniel. Pente-fino cancela 84\% de auxílio-doença e aposentadoria por invalidez. Valor econômico, 13 abr. 2017. Disponível em: https://bit.ly/2rWCDfb [https://www.valor.com.br/brasil/4937382/pente-fino-cancela-84-de-auxilio-doenca-eaposentadoria-por-invalidez].Acesso em $28 \mathrm{dez} .2018$.

CHAYES, Abram. The role of judge in public law litigation. Harvard Law Review, vol.89, no 7 , mai./1976, p.1281-1315.

CINTRA, Antonio Carlos de Araújo; GRINOVER, Ada Pellegrini; DINAMARCO, Cândido Rangel. Teoria Geral do Processo. 17ª ed. São Paulo: Malheiros, 2001.

CLARK, Bryan. Lawyers and Mediation. Berlin/Heidelberg: Springer-Verlag, 2012.

COLE, Daniel H. The Varieties of Comparative Institutional Analysis. Wisconsin Law Review, 2013, p. 383-409.

CONSELHO NACIONAL DE JUSTIÇA. Cem maiores litigantes - 2011. Disponível em: https://bit.ly/1xVcyXL [http://www.cnj.jus.br/images/pesquisasjudiciarias/pesquisa_100_maiores_litigantes.pdf] . Acesso em: 28 dez. 2018.

Cem maiores litigantes - 2012. Disponível em: https://bit.ly/1hRPJmr

[http://www.cnj.jus.br/images/pesquisasjudiciarias/Publicacoes/100_maiores_litigantes.pdf]. Acesso em: 28 dez. 2018.

. Justiça em Números - 2015: ano-base 2014. Brasília: CNJ, 2015. Justiça em Números - 2016: ano-base 2015. Brasília: CNJ, 2016. Justiça em Números - 2018: ano-base 2017. Brasília: CNJ, 2018. Relatório de Inspeção. NUPEMEC-CEJUSC Tribunal de Justiça do Estado de São Paulo. São Paulo: CNJ, março/2018. Disponível em: https://bit.ly/2Q7APK2 [http://www.cnj.jus.br/corregedoriacnj/inspecoes-correicoes/relatorios/category/5592018\#]. Acesso em: $28 \mathrm{dez} .2018$.

CONSTANTINO, Rodrigo. Justiça move quase 40 ações contra jornal após reportagem sobre salário de juízes: retaliação? Gazeta do Povo, 8 jun. 2016. Disponível em: https://bit.ly/2ThM1pq [http://www.gazetadopovo.com.br/rodrigo- 
constantino/artigos/justica-move-quase-40-acoes-contra-jornal-apos-reportagem-sobresalario-de-juizes-retaliacao/l. Acesso em: 28 dez. 2018

CORNWELL, ErinYork; POPPE, Emily S. Taylor; BEA, Megan Doherty. Networking in the Shadow of the Law: Informal Access to Legal Expertise through Personal Network Ties. Law and Society Review, vol.51, n 3, set./2017, p.635-668.

COSTA, Susana Henriques da. STF e os filtros ao acesso à Justiça: gestão processual ou vantagem ao grande litigante? Supremo em Pauta. Estado de S. Paulo, 18 set. 2014. Disponível em: https://bit.ly/2LFMvCV [https://politica.estadao.com.br/blogs/supremoem-pauta/stf-e-os-filtros-ao-acesso-a-justica-gestao-processual-ou-vantagem-ao-grandelitigante/]. Acesso em: 28 dez. 2018.

COUTINHO, Mateus. Juízes processam jornalistas que revelaram seus vencimentos. Estado de S. Paulo, 08 jun. 2016. Disponível em: https://bit.ly/22P6QHH [http://politica.estadao.com.br/blogs/fausto-macedo/juizes-processam-jornalistas-querevelaram-seus-supersalarios/l. Acesso em: 28 dez. 2018.

CRESPO, Mariana Hernández. A systemic perspective on ADR in Latin America: enhancing the shadow of the Law through citizen participation. Cardozo Journal of Conflict Resolution, vol. 10, outono 2008, p.91-129.

CUNHA, Alexandre dos Santos. Indicadores socioeconômicos e a litigiosidade. Brasília: 23 set. 2010. 12 slides. Apresentação em Powerpoint. Disponível em:

https://bit.ly/2Q3jNwB [http://www.cnj.jus.br/images/pesquisas-judiciarias/iii-seminariojustica-em-numeros/apre_alexandre_cunha_jn_2010.pdf]. Acesso em: 13 abr. 2017.

DEUTSCH, Morton. The Resolution of Conflict: Constructive and Destructive Processes. New Haven/ London: Yale University Press, 1973. [Também foi utilizada seguinte tradução parcial para o português: DEUTSCH, Morton. A resolução do conflito: processos construtivos e destrutivos. Tradução de Arthur Coimbra de Oliveira, com revisão de Francisco Schertel Mendes. In: AZEVEDO, André Gomma (org.). Estudos em arbitragem, mediação e negociação - Vol.3. Brasília: Brasília Jurídica, 2004, p. 29-98].

DINAMARCO, Cândido Rangel. A Instrumentalidade do Processo. $15^{\mathrm{a}}$ ed. São Paulo: Malheiros, 2013.

DINAMARCO, Cândido Rangel; LOPES, Bruno Vasconcelos Carrilho. Teoria Geral do Novo Processo Civil. São Paulo: Malheiros, 2016.

DUTRA, Bruno. INSS cancela R \$ 9,6 bilhões em aposentadorias e auxílios-doença irregulares. O Globo, 06 jun. 2018 e 04 out. 2018. Disponível em: https://glo.bo/2RjLypb [https://oglobo.globo.com/economia/inss-cancela-96-bilhoes-em-aposentadorias-auxiliosdoenca-irregulares-22858802]. Acesso em: 28 dez. 2018.

EDELMAN, Lauren B. Working Law: Courts, Corporations, and Symbolic Civil Rights. Livro eletrônico. Chicago/London: University of Chicago Press, 2016.

EDELMAN, Lauren B.; SUCHMAN, Mark C. When the "Haves" Hold Court: Speculations on the Organizational Internalization of Law. In: KRITZER, Herbert M.; 
SILBEY, Susan. In Litigation: Do the "Haves" Still Come Out Ahead. Stanford: Stanford University Press, 2003, p.290-341.

EDELMAN, Lauren B.; FULLER, Sally Riggs; MARA-DRITA, Iona. Diversity Rhetoric and the Managerialization of Law. American Journal of Sociology, vol. 106, $\mathrm{n}^{\circ} 6$, mai/2001, p.1589-1641.

ELGOIBAR, Patricia; EUWEMA, Martin; MUNDUATE, Lourdes. Conflict Management. Oxford Research Encyclopedia of Psychology, jun. 2017. Disponível em: https://bit.ly/2RdUjBp

[http://psychology.oxfordre.com/view/10.1093/acrefore/9780190236557.001.0001/acrefo re-9780190236557-e-5?rskey=c2jGaX\&result=1]. Acesso em: 28 dez. 2018.

ENGEL, David M. The Myth of the Litigious Society: Why We Don't Sue. Livro eletrônico. Chicago/Londres: The University of Chicago, 2016.

ESKRIDGE JR., William N. Expanding Chevron's Domain: A Comparative Institutional Analysis of the Relative Competence of Courts and Agencies to Interpret Statutes, Wisconsin Law Review, 2013, p.411-454.

ESTADO DE S. PAULO. Aumento de litigiosidade compromete mecanismos processuais. Estado de S. Paulo, $28 \mathrm{dez}$. 2015. Disponível em: https://bit.ly/2Q6mAoH [http://www.conjur.com.br/2015-dez-28/aumento-litigiosidade-compromete-mecanismosprocessuais]. Acesso em 28 dez. 2018.

. Explosão de litigiosidade. Estado de S. Paulo, 18 set. 2010. Disponível em: https://bit.ly/2VhsGqi [http://politica.estadao.com.br/noticias/geral,explosao-delitigiosidade,611970]. Acesso em 28 dez. 2018.

FARIA, José Eduardo. O Estado e o Direito depois da crise. $2^{\mathrm{a}}$ ed. São Paulo: Saraiva, 2016, no prelo.

O Sistema brasileiro de Justiça: experiência recente e futuros desafios. Estudos Avançados 18 (51), 2004, p.103-125.

FELDMAN, Eric. Law, Culture, and Conflict: Dispute Resolution in Postwar Japan. In: FOOTE, Daniel H. (ed.) Law in Japan: a Turning Point. Washington: University of Washington Press, 2007, p.50-79.

FELSTINER, William L. F. Avoidance as Dispute Processing: An Elaboration. Law and Society Review, vol.9, n.4, verão/1975, p.695-706.

Influences of Social Organization on Dispute Processing. Law and Society Review, vol.9, n.1, Litigation and Dispute Processing: Part one, outono/1974, p.63-94.

FELSTINER, William L. F.; ABEL, Richard L.; SARAT, Austin. The Emergence and Transformation of Disputes: Naming, Blaming, Claiming... Law \& Society Review, vol. 15, $\mathrm{n}^{\mathrm{o}}$ 3/4, Special Issue on Dispute Processing and Civil Litigation (1980-1981), p. 631654. 
FERNANDES, Adriana. Governo cancela R \$ 9,6 bilhões em benefícios irregulares. Estado de S. Paulo, 06 jun. 2018. Disponível em: https://bit.ly/2KDid6H [https://economia.estadao.com.br/noticias/geral,governo-cancela-r-9-6-bilhoes-embeneficios-irregulares, 70002390051].Acesso em: 28 dez. 2018.

FERRAZ, Léslie S.; GABBAY, Daniela Monteiro; ECONOMIDES, Kim; ASPERTI, Maria Cecilia de Araújo ; COSTA, Susana Henriques da ; LAURIS, Élida ; ALMEIDA, Frederico de ; CHASIN, Ana Carolina ; CUNHA, Luciana Gross ; TAKAHASHI, Bruno. Mesa de debates: Repensando o acesso à Justiça: velhos problemas, novos desafios. Revista de Estudos Empíricos em Direito, v. 4, 2017, p.174-212.

FERRAZ JR., Tércio Sampaio. O oficial e o inoficial: ensaio sobre a diversidade de universos jurídicos temporal e espacialmente concomitantes. In: Joaquim Falcão. (Org.). Invasões Urbanas: conflito de direito de propriedade. Livro Eletrônico. $2^{\mathrm{a}}$ ed. Rio de Janeiro: Editora FGV, 2008, pos. 2153-2254.

FGV DIREITO SP. Relatório ICJBrasil. $1^{\circ}$ trimestre/2014 - $4^{o}$ trimestre de 2014: Ano 06. São Paulo: FGV.

FISHER, Roger; URY, William; PATTON, Bruce. Como chegar ao sim. Tradução Vera Ribeiro e Ana Luiza Borges. $2^{\mathrm{a}}$ ed. Rio de Janeiro: Imago, 2005.

FISS, Owen. Contra o acordo. In: Um Novo Processo Civil: Estudos Norte-Americanos sobre Jurisdição, Constituição e Sociedade. Coordenação da tradução de Carlos Alberto de Salles. Tradução de Daniel Porto Godinho e Melina de Medeiros Rós. São Paulo: Revista dos Tribunais, 2004, p.121-145.

FIX-FIERRO, Héctor. Courts, Justice \& Efficiency: A Social-Legal Study of Economic Rationality in Adjudication. Portland: Hart Publishing, 2003.

FOLLETT, Mary Parker. Co-ordination. In: FOLLETT, Mary Parker. Freedom \& Coordination: Lectures in Business Organisation. Editado por L. Urwick et al. London: Management Publications Trust, 1949, p.61-76.

FONSECA, Juliana Pondé. Problemas Estruturais Do Judiciário: por um processo civil factível. Dissertação de Mestrado. Curitiba: Universidade Federal do Paraná, 2011.

FREITAS JR., Antonio Rodrigues de. Conflitos de Justiça e Limites da Mediação para a Difusão da Cultura da Paz. In: SALLES, Carlos Alberto de (org.). As grandes transformações do processo civil brasileiro: homenagem ao Professor Kazuo Watanabe. São Paulo: Quartier Latin, 2009, p.509-534.

. Conflitos intersubjetivos e apropriações sobre o justo. In: SILVA, Luciana Aboim Machado Gonçalves da (org.). Mediação de Conflitos. São Paulo: Atlas, 2013, p. 33-41.

FRIEDMAN, Lawrence M. Impact: How Law Affects Behavior. Livro eletrônico. Cambridge/ London: Harvard University Press, 2016.

Total Justice. New York: Russell Sage Foundation, 1994 [1985]. 
FRYDENBERG, Erica. Morton Deutsch: A Life and Legacy of Mediation and Conflict Resolution. Brisbane: Australian Academic Press, 2005.

FULLER, Lon. L. The Forms and Limits of Adjudication. Harvard Law Review, vol. 92, $\mathrm{n}^{\mathrm{o}} 2$, dez. 1978, p.353-409.

GABBAY, Daniela Monteiro. Litigância Repetitiva e Acesso à Justiça no Brasil: uma Nova Agenda de Pesquisa. In: FERRAZ, Leslie S. (coord.). Repensando o Acesso à Justiça: Estudos Internacionais. Vol. 1 - As Ondas de Cappelletti no Século XXI. Aracaju: Evocati, 2016, p.87107.

Mediação \& Judiciário no Brasil e nos EUA: Condições, Desafios e Limites para a institucionalização da Mediação no Judiciário. Brasília: Gazeta Jurídica, 2013.

Prévio requerimento administrativo como condição de acesso ao Judiciário: decisão boa para quem? Supremo em Pauta. Estado de S. Paulo, 05 set. 2014. Disponível em: https://bit.ly/2Q1FKXF [https://politica.estadao.com.br/blogs/supremo-em pauta/previo-requerimento-administrativo-como-condicao-de-acesso-ao-judiciariodecisao-boa-para-quem/]. Acesso em: 03 jan. 2019.

GALANTER, Marc. Access to Justice in a World of Expanding Social Capability. Fordham Urban Law Journal, vol. 37, $\mathrm{n}^{\circ}$ 1, 2009, p.115-128. [também foi utilizada a seguinte tradução para o português: Acesso à Justiça em um Mundo de Capacidade Social em Expansão. Tradução de João Eberhardt Francisco, Maria Cecília de Araújo Asperti e Susana Henriques da Costa Revista Brasileira de Sociologia do Direito, v. 2, $\mathrm{n}^{\mathrm{o}} 1$, jan./jun., 2015, p. 37-49].

Adjudication, Litigation, and Related Phenomena. In: LIPSON, Leon;

WHEELER, Stanton. Law and the Social Sciences. New York: Russell Sage Foundation, 1986, p.151-257.

Afterword: Explaining Litigation. Law and Society Review, vol. 9, n. 2,

Litigation and Dispute Processing: Part Two, inverno/1975, p.347-368.

1990, p.371-395.

Case Congregations and Their Careers. Law \& Society Review, vol. 24, $\mathrm{n}^{\circ} 2$,

Introduction: Compared to What? Assessing the Quality of Dispute

Processing. Denver University Law Review, vol. 66, n³, 1989, p.xi-xiv.

Introduction: Haves Ascendant. In: GALANTER, Marc. Why the Haves

Come Out Ahead: The Classic Essay and New Observations. New Orleans: Quid Pro Books, 2014, p.1-14.

. Jury Shadows: Reflections on the Civil Jury and the "Litigation Explosion". In: The American Civil Jury: Final Report of the 1986 Chief Justice Earl Warren Conference on Advocacy in the United States Washington. S.1.: The Roscoe PoundAmerican Trial Lawyers Foundation, 1987, p.14-42. 
Justice in Many Rooms: Courts, Private Ordering and Indigenous Law. Madison: University of Wisconsin, s/d. Reimpressão do artigo publicado no Journal of Legal Pluralism, n 19, 1981, p.1-47.

Planet of the APs: Reflections on the Scale of Law and Its Users, Buffalo Law Review, vol. 53, n 5, p. 1369-1418.

. Reading the Landscape of Disputes: What We Know and Don't Know (And Think We Know) About Our Allegedly Contentious and Litigious Society. UCLA Law Review, vol.31, 1983, p.4-71.

1, 1986, p.3-39.

. The Day After the Litigation Explosion, Maryland Law Review, vol. 46, $\mathrm{n}^{\circ}$

. The Legal Malaise; or, Justice Observed. Law \& Society Review, vol. 19, $\mathrm{n}^{\circ}$ 4, 1985, p. 537-556.

The Modernization of Law. In: WEINER, Myron (ed.). Modernization. New York: Basic Books, 1966, p. 153-165. [também foi utilizada a seguinte tradução para o português:: A Modernização do Direito. Traduzido por Maria da Conceição Barbosa. In: SOUTO, Cláudio; FALCÃO, Joaquim (ed.). Sociologia e Direito: leituras básicas de sociologia jurídica. São Paulo: Pioneira, 1980, p.233-241].

.The Portable Soc 2; or, What to Do until the Doctrine Comes. In: MACALOON, John J. (ed.). General Educaton in the Social Sciences: Centennial Reflections on the College of the University of Chicago. Chicago/ Londres: University of Chicago Press, 1992, p.246-261.

. The Radiating Effects of Courts. In: BOYUM, Keith O.; MATHER, Lynn. Empirical Theories About Courts. 2 ed. New Orleans: Quid Pro Books, 2015, 121-146.

. The Three-Legged Pig: Risk Redistribution and Antinomianism in American Legal Culture. Mississippi College Law Review, vol. 22, 2002-2003, p.47-55.

. The Transnational Traffic in Legal Remedies. JASANOFF, Sheila (ed.). Learning from Disaster: Risk Management after Bhopal. Philadelphia: University of Pennsylvania Press, p.133-157.

. The Travails of Total Justice. In: GORDON, Robert W.; HORWITZ, Morton J. (ed.). Law, Society and History: Themes in the Legal Sociology and Legal History of Lawrence M. Friedman. New York: Cambridge University Press, 2011, p.103117.

. Why the "Haves" Come out Ahead: Speculations on the Limits of Legal $\overline{\text { Change. Law }}$ and Society Review, 1974, vol. 9, $\mathrm{n}^{\circ}$ 1, p.95-160. [também foi utilizada a seguinte tradução para o português:: Por que "quem tem" sai na frente: Especulações sobre os limites da transformação no direito. Organização e tradução de tradução de Ana Carolina Chasin. São Paulo : FGV Direito SP, 2018. Disponível em: https://bit.ly/2GKMEGC, http://hdl.handle.net/10438/25816. Acesso em: 28 dez. 2018]. 
GALANTER, Marc; EDELMAN, Lauren. Law: The Social-Legal Perspective. In: WRIGHT, James (ed.). International Encyclopedia of the Social \& Behavioral Sciences, vol. 13. $2^{\text {a }}$ ed. Amsterdam: Elvesier, 2015, p.604-613.

GALANTER, Marc; ASPERTI, Maria Cecília de Araujo; GABBAY, Daniela Monteiro; SALINAS, Natasha Schmitt Caccia; SILVA, Paulo Eduardo Alves da. Talking About the Limits of Legal Change: an interview with Marc Galanter. Revista de Estudos Empíricos em Direito, vol. 1, n. 2, jul 2014, p. 200-211.

GARNER, Bryan A. (ed.). Black's Law Dictionary. 10a ed. Saint Paul: Thomson Reuters, 2014.

GERSON, Stuart M. The Burden of Metaphor, inédito, s/d, com base em cópia do arquivo pessoal de Marc Galanter, p.1-11.

GHOSH, Shubha. Komesar's Razor: Comparative Institutional Analysis in a World of Networks. Wisconsin Law Review, 2013, esp.465-466.

GIANNETTI, Eduardo. Vícios privados, benefícios públicos?: A ética na riqueza das nações. Livro eletrônico. São Paulo, Companhia das Letras, 2001 [1993].

GORDON, Robert W. Afterword: How the Haves Stay Ahead. In: GALANTER, Marc. Why the Haves Come Out Ahead: The Classic Essay and New Observations. New Orleans: Quid Pro Books, 2014, p.111-127.

GRAU, Eros Roberto. $O$ direito posto e o direito pressuposto. $4^{\mathrm{a}}$ ed. São Paulo: Malheiros, 2002.

GRINOVER, Ada Pellegrini. Ensaio sobre a processualidade - Fundamentos para uma nova teoria geral do processo. Brasília: Gazeta Jurídica, 2016.

Os Métodos Consensuais de Solução de Conflitos no Novo CPC. IN: VVAA. O Novo Código de Processo Civil: questões controvertidas. São Paulo, Atlas, 2015, p. 1-21.

GRINOVER, Ada Pellegrini; WATANABE, Kazuo; COSTA, Susana Henriques da (coord.). O Processo para Solução de Conflitos de Interesse Público. Salvador: JusPodivm, 2017.

GRINOVER, Ada Pellegrini; WATANABE, Kazuo; LAGRASTA NETO, Caetano (coord.). Mediação e Gerenciamento do Processo. São Paulo: Atlas, 2008.

GUIMARÃES, Amanda de Araujo. Incidente de Resolução de Demandas Repetitivas: Soluções e Limites. Dissertação de Mestrado. São Paulo: Universidade de São Paulo, 2017.

HARARI, Yuval Noah. Homo Deus: uma breve história do amanhã. Tradução de Paulo Geiger. Livro Eletrônico. São Paulo: Companhia das Letras, 2015. 
INSTITUTO BRASILEIRO DE GEOGRAFIA E ESTATÍSTICA. Brasil em Números. Vol. 26. Rio de Janeiro: IBGE, 2018.

INSTITUTO DE PESQUISA ECONÔMICA APLICADA. Acesso à Justiça Federal: dez anos de juizados especiais. Brasília: Conselho da Justiça Federal, Centro de Estudos Judiciários, 2012.

. Sistema de Indicadores de Percepção Social - Justiça. Brasília: IPEA,

2011.

JUNQUEIRA, Eliane Botelho. Acesso à Justiça: um olhar retrospectivo. Revista Estudos Históricos, n.18, 1996, p.389-402.

. Faculdades de Direito ou Fábricas de Ilusão? Rio de Janeiro: Instituto de Direito e Sociedade/ Letra Capital, 1999.

KAFKA, Franz. Diante da lei. In: Um médico rural. Tradução de Modesto Carone. $1^{\text {a }}$ reimpr. São Paulo: Companhia das Letras, 2001, p.27-29.

KAWASHIMA, Takeyoshi. Dispute Resolution in Contemporary Japan. In: MEHREN, Arthur Taylor von. Law in Japan: The Legal Order in a Changing Society. Cambridge: Harvard University Press, 1963, p.41-71.

KOJIMA, Takeshi. Civil Procedure and ADR in Japan. Tokyo: Chuo University Press, 2004.

KOMESAR, Neil. Imperfect Alternatives: Choosing Institutions in Law, Economics and Public Policy. Chicago: University of Chicago, 1994.

. Injuries and Institutions: Tort Reform, Tort Theory, and Beyond. New York University Law Review, vol. 65, abr. 1990, p. 23-77.

A Job for the Judges: The Judiciary and the Constitution in a Massive and Complex Society. Michigan Law Review, vol. 86, fev. 1988, p.657-721.

Law's Limits: Rule of Law and the Supply and Demand of Rights. New York: Cambridge University Press, 2001.

The essence of economics: law, participation and institutional choice (two ways). In: BATIE, Sandra S.; MERCURO, Nicholas. Alternative Institutional Structures: evolution and impact. London/New York: Routledge, 2008, p.165-186.

. The Logic of the Law and the Essence of Economics: Reflections on Forty Years on the Wilderness. Wisconsin Law Review, 2013, p.265-338.

The Perils of Pandora: Further Reflections on Institutional Choice. Law and Social Inquiry, vol.22, 1997, p. 995-1009. 
Toward an Economic Theory of Conflict Choice. Working Paper 1979-2. Madison: University of Wisconsin Law School, Disputes Processing Research Program, 1979.

KOMESAR, Neil; WAGNER, Wendy. The Administrative Process From The Bottom Up: Reflections On The Role, If Any, For Judicial Review. Administrative Law Review, vol.69, 2017, p. 891-948.

KRIESBERG, Louis. The Evolution of Conflict Resolution. In: BERCOVITCH, Jacob; KREMENYUK, Victor; ZARTMAN, I. William (ed.) The SAGE Handbook of Conflict Resolution. Los Angeles/London/New Delhi/Singapore/Washington D.C.: SAGE, 2009, p.15-32.

KRISLOV, Samuel. Theoretical Perspectives on Case Load Studies: A Critique and a Beginning. In: BOYUM, Keith O.; MATHER, Lynn. Empirical Theories About Courts. $1^{\circ}$ reimpr. Quid Pro: New Orleans, 2015, p.167-194.

LADEUR, Karl-Heinz. The Emergence of Global Administrative Law and the Evolution of General Administrative Law. 14 set. 2010. Disponível em: https://bit.ly/2GGZwgV [http://works.bepress.com/karlheinz_ladeur/1/]. Acesso em: 28 dez. 2018.

LAGRASTA, Valeria Ferioli. Os Centros Judiciários de Solução Consensual de Conflitos (CEJUSCS) e seu Caráter de Tribunal Multi Portas. In: BACELLAR, Roberto Portugal; LAGRASTA, Valeria Ferioli (coord.). Conciliação e Mediação: ensino em construção. São Paulo: IPAM/ ENFAM, 2016, p.95-118.

A Resolução n. 125 do Conselho Nacional de Justiça: Origem, Objetivos, Parâmetros e Diretrizes para a Implantação Concreta. In: RICHA, Morgana de Almeida; PELUSO, Antonio Cezar (coord.). Conciliação e mediação: estruturação da política judiciária nacional. Rio de Janeiro: Forense, 2011, p. 229-249.

LAHAV, Alexandra. In Praise of Litigation. Livro eletrônico. New York: Oxford University Press, 2017.

LAZZERI, Thais. Juízes e promotores movem dezenas de ações contra jornalistas que divulgaram seus salários. Época, 08 jun. 2016, atualizado em 09 jun. 2016. Disponível em: https://glo.bo/2Q7LuUW [http://epoca.globo.com/tempo/noticia/2016/06/juizes-epromotores-movem-dezenas-de-acoes-contra-jornalistas-que-divulgaram-seussalarios.html]. Acesso em: 28 dez. 2018.

LEVRERO, Mario. O romance luminoso. Tradução de Antônio Xerxenesky. Livro eletrônico. São Paulo: Companhia das Letras, 2018.

LEWANDOWSKI, Ricardo. Discurso de Posse na Presidência do Supremo Tribunal Federal, 10 set. $2014 . \quad$ Disponível em: https://bit.ly/2GLueFy [http://www.stf.jus.br/arquivo/cms/noticianoticiastf/anexo/discursoministrorl.pdf] Acesso em 28 dez. 2018.

LIPSKY, Michael. Street-Level Bureaucracy: dilemmas of the individual in public services. 30th anniversary expanded edition. New York: Russel Sage Foundation, 2010. 
LORENCINI, Marco Antônio Garcia Lopes. "Sistema Multiportas": Opções para tratamento de conflitos de forma adequada. In: SALLES, Carlos Alberto de; LORENCINI, Marco Antônio Garcia Lopes; SILVA, Paulo Eduardo Alves da (coord.). Negociação, Mediação e Arbitragem - Curso Básico para Programas de Graduação em Direito. Rio de Janeiro: Forense/ São Paulo: Método, 2012, p.57-85.

MACAULAY, Stewart. Non-Contractual Relations in Business: A Preliminary Study. American Sociological Review, vol. 28, nº 1, fev.1963, p.55-67.

MALLOY, Robin Paul. Law and Economics: A Comparative Approach to Theory and Practice. St. Paul: West Publishing, 1990.

MANCUSO, Rodolfo de Camargo. Acesso à justiça: condicionantes legítimas $e$ ilegítimas. $2^{\mathrm{a}}$ ed. São Paulo: Revista dos Tribunais, 2015.

A Resolução dos Conflitos e a Função Judicial no Contemporâneo Estado de Direito. São Paulo: Revista dos Tribunais, 2009.

MANUS, Pedro Paulo Teixeira. Avalanche de processos atrasa bons julgamentos ou gera decisões sem cuidado. Consultor Jurídico, 03 fev. 2017. Disponível em: https://bit.ly/2EQeu2g [https://www.conjur.com.br/2017-fev-03/reflexoes-trabalhistasavalanche-processos-atrasa-bons-julgamentos-ou-gera-decisoes-cuidado]. Acesso em 28 dez.. 2018.

MARCONDES, Antonio Fernando Mello. Os Dispute Boards e os Contratos de Construção. In: BAPTISTA, Luiz Olavo; PRADO, Mauricio Almeida (org.). Construção Civil e Direito. São Paulo: Lex Magister, 2011, p.123-148.

MASSONI, Túlio de Oliveira. Os Desafios do Trabalhador em Face da (Indevida) Alta Previdenciária. Revista Brasileira de Previdência. São Paulo: Universidade Federal de São Paulo, $1^{\mathrm{a}}$ ed., nov. 2012, p.55-84.

MATHER, Lynn; YNGVESSON, Barbara. Disputes, Social Construction and Transformation of. In: WRIGHT, James (ed.). International Encyclopedia of the Social \& Behavioral Sciences, vol. 6. $2^{\mathrm{a}}$ ed. Amsterdam: Elvesier, 2015, p.560-566.

Language, Audience, and the Transformation of Disputes. Law \& Society Review, Vol. 15, Number 3-4, 1980-1981, p.775-821.

MATTEI, Ugo. Access to Justice. A Renewed Global Issue?, vol. 11.3 Electronic Journal Of Comparative Law, dec. 2007, p.1-25.. Disponível em: https://bit.ly/2Sqz1h8 [http://www.ejcl.org/113/article113-14.pdf]. Acesso em: 28 dez. 2018.

MENDONÇA, Fernando Hideki. Entrando em Consenso sobre a Obrigatoriedade da Audiência de Conciliação ou Mediação Preliminar. Tese de Láurea. São Paulo: Universidade de São Paulo, 2016.

MENKEL-MEADOW, Carrie. Mothers and Fathers of Invention: The Intellectual Founders of ADR. Ohio State Journal on Dispute Resolution, vol. 16, 2000, p.1-37. 
MEYN, Ion. Why Civil and Criminal Procedure are So Different: A Forgotten History. Fordham Law Review, vol. 86, n 2, 2017, p.697-736.

MINISTÉRIO DA FAZENDA. Reformas Microeconômicas e Crescimento de Longo Prazo. Brasília: Ministério da Fazenda, dez. 2004.

MNOOKIN, Robert H.; KORNHAUSER, Lewis. Bargaining in the Shadow of the Law: The Case of Divorce. The Yale Law Journal, vol. 88, 1979, p.950-997.

MOORE, Sally Falk. Law and Social Change: The Semi-Autonomous Social Field as an Appropriate Subject of Study. Law and Society Review, vol. 7, n 4, verão/1973, p.719746.

MOREIRA, José Carlos Barbosa. Privatização do Processo? Revista da EMERJ, v.1, nº 3, 1998, p.13-25.

MORRILL, Calvin; EDELMAN, Lauren B.; TYSON, Karolyn; ARUM, Richard. Legal Mobilization in Schools: The Paradox of Rights and Race among Youth. Law \& Society Review, vol. 44, 2010, p.651-694.

NAGAO, Paulo Issamu. O Papel do Juiz na Efetividade do Processo Civil Contemporâneo. São Paulo: Malheiros, 2016.

NEVES, Vitor. Pente-fino no INSS já gerou quase 14 bilhões de economia. Jornal da USP, 21 nov. 2018. Disponível em: $\underline{\mathrm{https}: / / \mathrm{bit} .1 \mathrm{y} / 2 \mathrm{VhtDim}}$ [https://jornal.usp.br/atualidades/pente-fino-no-inss-ja-gerou-quase-14-bilhoes-deeconomia/l.Acesso em: $28 \mathrm{dez} .2018$.

POSNER, Richard. Divergent Paths: the Academy and the Judiciary. Livro eletrônico. Cambridge: Harvard University Press, 2016.

PROCURADORIA-GERAL FEDERAL. PROCURADORIA FEDERAL ESPECIALIZADA JUNTO AO INSS. Projeto Integrado Benefícios por Incapacidade: Adequação dos Recursos Públicos despendidos pelo INSS com pagamento de benefícios de Auxílio-Doença concedidos por decisão judicial. Brasília: fev. 2016. 14 slides. Apresentação em Powerpoint.

PURCELL JR., Edward A. Litigation and Inequality: Federal Diversity Jurisdiction in Industrial America, 1870-1958. New York: Oxford University Press, 1992.

RAYMUNDO, Adhemar. O Processo Penal à Luz do Pensamento "Carneluttiano". In: SUPERIOR TRIBUNAL DE JUSTIÇA. Ministro Adhemar Raymundo da Silva: Homenagem Póstuma. Brasília: Superior Tribunal de Justiça, 2007, p.93-101. [Publicado originalmente em Revista dos Tribunais, v. 51, jan./fev. 1955, p. 12-22].

RESNIK, Judith. Many Doors? Closing Doors? Alternative Dispute Resolution and Adjudication. The Ohio State Journal on Dispute Resolution, vol. 10, n. 2, 1995, p.211266. 
Mediating Preferences: Litigant Preferences for Process and Judicial Preferences for Settlement. Journal of Dispute Resolution, vol. 2002, n 1, 2002, p.155169.

RICHA, Morgana de Almeida. Evolução da Semana Nacional de Conciliação como Consolidação de um Movimento Nacional Permanente da Justiça Brasileira. In: PELUSO, Antonio Cezar; RICHA, Morgana de Almeida (Coord.). Conciliação $e$ Mediação: estruturação da política judiciária nacional. Rio de Janeiro: Forense, 2011, p. 61-72.

SALLES, Carlos Alberto de. Arbitragem em Contratos Administrativos. Rio de Janeiro: Forense, 2011.

. Duas faces da proteção judicial dos direitos sociais no Brasil. In: SALLES, Carlos Alberto de (org.). As grandes transformações do processo civil brasileiro: homenagem ao Professor Kazuo Watanabe. São Paulo: Quartier Latin, 2009, p.807-818.

Entre a Eficiência e a Equidade: Bases Conceituais para um Direito Processo Coletivo. Revista de Direitos Difusos, vol.36, Direito Processual Coletivo I, mar./abr. 2006, p. 13-31.

Tribunais, 1998.

Execução Judicial em Matéria Ambiental. São Paulo: Revista dos

- Mecanismos Alternativos de Solução de Controvérsias e Acesso à Justiça: a Inafastabilidade da Tutela Jurisdicional Recolocada. In: FUX, Luiz; NERY JR, Nelson; WAMBIER, Teresa Arruda Alvim (coord.). Processo e Constituição: Estudos em Homenagem ao Professor José Carlos Barbosa Moreira. São Paulo: Revista dos Tribunais, 2006, p. 779-792.

Nos braços do Leviatã: os Caminhos da Consensualidade e o Judiciário Brasileiro. In: BARBUGIANI, Luiz Henrique Sormani. Mediação e Arbitragem no Âmbito Público e Privado: perspectivas e limitações: estudos em homenagem aos 800 anos da Universidade de Salamanca. Rio de Janeiro: Lumen Juris, 2018,especialmente p.87-109.

. Processo Civil de Interesse Público. In: SALLES, Carlos Alberto de (org.). Processo Civil e Interesse Público: O processo como instrumento de defesa social. São Paulo: Revista dos Tribunais, 2003, p.39-77.

Processo: Procedimento Dotado de Normatividade - uma Proposta de Unificação Conceitual. In: ZUFELATO, Camilo; YARSHELL, Flávio Luiz (org.). 40 anos da Teoria Geral do Processo no Brasil: Passado, presente e futuro. São Paulo: Malheiros, 2013, p.201-217.

SANDER, Frank E. A. The Multi-Door Courthouse: Settling disputes in the year 2000. 3 Barrister 18, 1976, p.20-21 e 40-42. 
Varieties of Dispute Processing. In: LEVIN, A. Leo; WHEELER, Russell R. The Pound Conference: Perspectives on Justice in the Future. Saint Paul: West Publishing, 1979, p.65-87.

SANDER, Frank E. A.; CRESPO, Mariana Hernandez. A Dialogue Between Professors Frank Sander and Mariana Hernandez Crespo: Exploring the Evolution of the Multi-Door Courthouse. University of St. Thomas Law Journal, vol. 5, n³, 2008, p.665-674.

SANTOS, Boaventura de Sousa. Toward a New Legal Common Sense. $2^{\text {a }}$ ed. Londres: LexisNexis Butterworths, 2002.

SANTOS, Wanderley Guilherme. Razões da Desordem. Rio de Janeiro: Rocco, 1994.

SARAT, Austin. The Litigation Explosion, Access to Justice, and Court Reform: Examining the Critical Assumptions. Rutgers Law Review, vol. 37, 1984-1985, p.319336.

SCHLANGER, Margo. Jail Strip-Search Cases: Patterns and Participants. Law and Contemporary Problems, vol. 71, 2008, p.65-88.

SEUL, Jeffrey R. Litigation as a Dispute Resolution Alternative. In: MOFFITT, Michael L.; BORDONE, Robert (ed.). The Handbook of Dispute Resolution. São Francisco: Jossey-Bass, 2005, p. 336-357.

SHARAFI, Mitra. Justice in Many Rooms Since Galanter: De-Romanticizing Legal Pluralism Through the Cultural Defense. Law and Contemporary Problems, vol. 71, 2008, p.139-146.

SICA, Heitor Vitor Mendonça. Congestionamento Viário e Congestionamento Judiciário. Revista de Processo, vol.236, out. 2014, p.13-26 (10 págs. na versão eletrônica).

Perspectivas Atuais da "Teoria Geral do Processo", s/d, arquivo do autor,

p.1-28.

SILVA, Fabio de Sá e. Vetores, Desafios e Apostas possíveis na Pesquisa Empírica em Direito no Brasil. Revista de Estudos Empíricos em Direito, vol.3, n¹, 2016, p. 24-53.

SILVA, Paulo Eduardo Alves da. Acesso à justiça, litigiosidade e o modelo processual civil brasileiro. Tese de Livre-Docência. Ribeirão Preto: Faculdade de Direito de Ribeirão Preto, Universidade de São Paulo

Solução de controvérsias: métodos adequados para resultados possíveis e métodos possíveis para resultados adequados. In: SALLES, Carlos Alberto de; LORENCINI, Marco Antônio Garcia Lopes; SILVA, Paulo Eduardo Alves da (coord.). Negociação, Mediação e Arbitragem - Curso Básico para Programas de Graduação em Direito. Rio de Janeiro: Forense/ São Paulo: Método, 2012, p.1-25.

SORJ, Bernardo. A Nova Sociedade Brasileira. $3^{\mathrm{a}}$ ed. Rio de Janeiro: Jorge Zahar Editor, 2006. 
SOURDIN, Tania. The Role of the Courts in the New Justice System. Yearbook on Arbitration and Mediation, vol. 7, 95, 2015. Disponível em: https://bit.ly/2Akj5WJ [http://elibrary.law.psu.edu/cgi/viewcontent.cgi?article $=1033 \&$ context=arbitrationlawrevi ewl. Acesso em 28 dez. 2018.

SURGIK, Aloísio. A Origem da Conciliação. Tese de Doutorado. São Paulo: Faculdade de Direito da Universidade de São Paulo, 1984.

TALESH, Shauhin A. How Dispute Resolution System Design Matters: An Organizational Analysis of Dispute Resolution Structures and Consumer Lemon Laws. Law \& Society Review, Vol. 46, no 3, 2012, p.463-496.

. How the "Haves" Come out Ahead in the Twenty-First Century. DePaul Law Review, vol. 62, 2013, p.519-554.

TAKAHASHI, Bruno. Aspectos Processuais dos Benefícios Previdenciários por Incapacidade. Revista CEJ, ano XVI, n 56, jan./abr. 2012, p.28-43.

Desequilíbrio de Poder e Conciliação: o papel do terceiro facilitador em conflitos previdenciários. Brasília: Gazeta Jurídica, 2016.

. De novo, os meios consensuais no Novo CPC. Revista Científica Virtual da ESA, vol. 23, p. 24-33, 2016. Disponível em: https://bit.ly/2Ve0XGG [https://www.esaoabsp.edu.br/ckfinder/userfiles/files/RevistaVirtual/Revista\%20Cienti\% CC\%81fica\%20ESAOABSP\%20Ed\%2023.pdf]. Acesso em: 28 dez. 2018.

Entre a liberdade e a autoridade: os meios consensuais no novo Código de Processo Civil. Revista de Processo, vol. 264, 2017, p. 497-522.

Onde estão os dados? Palpites sobre a importância da pesquisa empírica em Direito Previdenciário em tempos de reforma. In: BERWANGER, Jane Lucia Wilhelm; SERAU JR., Marco Aurélio; FOLMANN, Melissa. Previdência Social? Porto Alegre: Lex Magister, 2016, p.13-25.

TARTUCE, Fernanda. Conciliação em juízo: o que (não) é conciliar? In: SALLES, Carlos Alberto de; LORENCINI, Marco Antônio Garcia Lopes; SILVA, Paulo Eduardo Alves da (coord.). Negociação, Mediação e Arbitragem - Curso Básico para Programas de Graduação em Direito. Rio de Janeiro: Forense/ São Paulo: Método, 2012, p.149-178.

THALER, Richard H.; SUNSTEIN, Cass R. Nudge: Improving Decisions About Health, Wealth, and Happiness. Livro Eletrônico. New York: Penguin Books, 2009.

THEODORO JR., Humberto; NUNES, Dierle; BAHIA, Alexandre Melo Franco; PEDRON, Flávio Quinaud. Novo CPC - Fundamentos e sistematização. $2^{\mathrm{a}}$ ed. Rio de Janeiro, Forense, 2015. 
URWICK, L. Preface. In: FOLLETT, Mary Parker. Freedom \& Co-ordination: Lectures in Business Organisation. Editado por L. Urwick et al. London: Management Publications Trust, 1949, p.vii-viii.

VAZ, Paulo Afonso Brum. Conciliações nos conflitos sobre direitos da Seguridade Social. Revista de Doutrina da $4^{a}$ Região. Porto Alegre: Tribunal Regional Federal da $4^{\mathrm{a}}$ Região, n. 43, ago. 2011. Disponível em: https://bit.ly/2Ag0vio [http://www.revistadoutrina.trf4.jus.br/index.htm?http://www.revistadoutrina.trf4.jus.br/a rtigos/edicao043/paulo_vaz.htmll. Acesso em: 28 dez. 2018.

VIANNA, Luiz Werneck. Não há limites para a patológica judicialização da política. Estado de S. Paulo, 03 jan. 2016. Disponível em: https://bit.ly/2GTOYLg [http://www.conjur.com.br/2016-jan-03/luiz-werneck-vianna-nao-limites-judicializacaopolitical. Acesso em: 28 dez. 2018.

VOSS, Thomas R. Institutions. In: WRIGHT, James (ed.). International Encyclopedia of the Social \& Behavioral Sciences, vol. 12. 2a ed. Amsterdam: Elvesier, 2015, p.190-195.

WAGNER, Wendy. The Participation-Centered Model Meets Administrative Process. Wisconsin Law Review, 2013, p.671-694.

WATANABE, Kazuo. Acesso à justiça e sociedade moderna. In: GRINOVER, Ada Pellegrini; DINAMARCO, Cândido Rangel; WATANABE, Kazuo (org.). Participação e Processo. São Paulo: Revista dos Tribunais, 1988, p.128.

Acesso à ordem jurídica justa: conceito atualizado de acesso à justiça, processos coletivos e outros estudos. Belo Horizonte: Del Rey, 2019.

Cognição no Processo Civil. $4^{\mathrm{a}}$ ed. São Paulo: Saraiva, 2012.

. Cultura da sentença e cultura da pacificação. In: YARSHELL, Flávio Luiz; MORAIS, Maurício Zanoide (org.). Estudos em Homenagem à Professora Ada Pellegrini Grinover. São Paulo: DPJ, 2005, p.684-690.

Depoimento. Cadernos FGV Projetos - Solução de Conflitos. Abril/ Maio 2017. Rio de Janeiro: FGV, 2017, p.22-29.

Filosofia e Características Básicas do Juizado Especial de Pequenas Causas. In: WATANABE, Kazuo (coord.). Juizado Especial de Pequenas Causas: Lei ${ }^{\circ}{ }^{\circ}$ 7.244, de 7 de novembro de 1984. São Paulo: Revista dos Tribunais, 1985, p.1-7.

A mentalidade e os meios alternativos de solução de conflitos no Brasil. In: GRINOVER, Ada Pellegrini; WATANABE, Kazuo; LAGRASTA NETO, Caetano (coord.). Mediação e Gerenciamento do Processo. São Paulo: Atlas, 2008, p. 6-10.

WATANABE, Kazuo; SANTANA, Daldice; TAKAHASHI, Bruno. Comentários aos artigos 24 a 29 da Lei de Mediação. In: CABRAL, Trícia Navarro Xavier; CURY, Cesar Felipe. Lei de Mediação Comentada Artigo por Artigo: dedicado à memória da Prof ${ }^{a}$ Ada Pellegrini Grinover. Indaiatuba: Foco, 2018, p.139-155. 
WIZIACK, Julio; PRADO, Maeli. Pente-fino corta R \$ 10 bi em gastos irregulares com Bolsa Família, aposentadoria e auxílio-doença. Folha de S. Paulo, 24.jul.2018. Disponível em: https://bit.ly/2LkyLkj [https://www1.folha.uol.com.br/mercado/2018/07/pente-fino-corta-r-10-bi-em-gastoirregular-com-57-mi-de-beneficiarios.shtmll.Acesso em: $28 \mathrm{dez} .2018$.

YOSHIMURA, Ryu. A Dualidade do "Liberal" no Neoliberalismo e da Solidariedade Local: um Estudo de Caso do Gerenciamento Individual de Fazendeiros Nikkeis e da Organização de Cooperativas Agrícolas no Sudeste Brasileiro. Tradução de Bruno Takahashi e revisão da tradução de Olivia Yumi Nakaema. IN: ODA, Ernani; NAKAEMA, Olivia Yumi; NABESHIMA, Yuri Kuroda (org.). Novos Temas de Pesquisa em Estudos Japoneses. Curitiba: Juruá, 2019, p.171-188.

YOSHINAGA, Gilberto. Pente-fino no INSS detecta até 'cego' que é motorista. Agora, 15 mai. 2018. Disponível em: https://bit.ly/2s11oGV [http://www.agora.uol.com.br/grana/2018/05/1968415-pente-fino-no-inss-detecta-atecego-que-e-motorista.shtml].Acesso em: 07 dez. 2018.

ZAPPAROLLI, Célia Regina. Agir contra si - Acrasia - e a Mediação de Conflitos. In: SOUZA, Luciane Moessa de (coord.). Mediação de Conflitos: novo paradigma de acesso à justiça. $2^{\mathrm{a}}$ ed. Santa Cruz do Sul: Essere nel Mondo, 2015, p.317-330. 